TITLE:

\title{
Identification of an antiviral component from the venom of the scorpion Liocheles australasiae using transcriptomic and mass spectrometric analyses
}

\section{AUTHOR(S):}

Miyashita, Masahiro; Mitani, Naoya; Kitanaka, Atsushi; Yakio, Mao; Chen, Ming; Nishimoto, Sachiko; Uchiyama, Hironobu; ... Hotta, Hak; Nakagawa, Yoshiaki; Miyagawa, Hisashi

\section{CITATION:}

Miyashita, Masahiro ... [et al]. Identification of an antiviral component from the venom of the scorpion Liocheles australasiae using transcriptomic and mass spectrometric analyses. Toxicon 2021, 191: 25-37

\section{ISSUE DATE:}

2021-02

\section{URL:}

http://hdl.handle.net/2433/266820

\section{RIGHT:}

(C) 2021. This manuscript version is made available under the Creative Commons Attribution-NonCommercialNoDerivatives 4.0 International 4.0 license.; The full-text file will be made open to the public on 1 February 2022 in accordance with publisher's 'Terms and Conditions for Self-Archiving'.; This is not the published version. Please cite only the published version. この論文は出版社版でありません。引用の際には出版社版をご確認ご利用ください。 
1 Identification of an antiviral component from the venom of the scorpion

2 Liocheles australasiae using transcriptomic and mass spectrometric analyses

5 Masahiro Miyashita ${ }^{1 *}$, Naoya Mitani $^{1}$, Atsushi Kitanaka ${ }^{1}$, Mao Yakio ${ }^{1}$, Ming Chen ${ }^{2}$,

6 Sachiko Nishimoto ${ }^{3}$, Hironobu Uchiyama ${ }^{4}$, Masayuki Sue ${ }^{5}$, Hak Hotta ${ }^{2,3}$, Yoshiaki

$7 \quad$ Nakagawa $^{1}$, and Hisashi Miyagawa ${ }^{1}$

$8 \quad{ }^{1}$ Graduate School of Agriculture, Kyoto University, Kyoto 606-8502, Japan

$9 \quad{ }^{2}$ Graduate School of Health Sciences, Kobe University, Kobe 650-0047, Japan

$10{ }^{3}$ Faculty of Clinical Nutrition and Dietetics, Konan Women's University, Kobe 658-0001, 11 Japan

${ }^{4}$ NODAI Genome Research Center, Tokyo University of Agriculture, Tokyo 156-8502, 13 Japan

${ }^{5}$ Department of Agricultural Chemistry, Tokyo University of Agriculture, Tokyo 1568502, Japan

*Corresponding author: e-mail; miyashita.masahiro.6e@kyoto-u.ac.jp

Postal address; Kitashirakawa Oiwakecho Sakyo-ku, Kyoto 606-8502, Japan

\section{Abstract}

Scorpion venom contains a variety of biologically active peptides. Among them, neurotoxins are major components in the venom, but it also contains peptides that show antimicrobial activity. Previously, we identified three insecticidal peptides from the venom of the Liocheles australasiae scorpion, but activities and structures of other venom components remained unknown. In this study, we performed a transcriptome analysis of the venom gland of the scorpion L. australasiae to gain a comprehensive understanding of its venom components. The result shows that potassium channel toxin-like peptides were the most diverse, whereas only a limited number of sodium channel toxin-like peptides were observed. In addition to these neurotoxin-like peptides, many non- 
30 disulfide-bridged peptides were identified, suggesting that these components have some 31 critical roles in the L. australasiae venom. In this study, we also isolated a component 32 with antiviral activity against hepatitis $\mathrm{C}$ virus using a bioassay-guided fractionation 33 approach. By integrating mass spectrometric and transcriptomic data, we successfully 34 identified LaPLA $2-1$ as an anti-HCV component. LaPLA A $_{2}-1$ is a phospholipase $\mathrm{A}_{2}$ having 35 a heterodimeric structure that is N-glycosylated at the N-terminal region. Since the 36 antiviral activity of $\mathrm{LaPLA}_{2}-1$ was inhibited by a PLA 2 inhibitor, the enzymatic activity of $\mathrm{LaPLA}_{2}-1$ is likely to be involved in its antiviral activity.

\section{Keywords}

40 bioactive peptide; glycosylation; hepatitis C; phospholipase; venom gland 


\section{Introduction}

Scorpions use their venom to capture their prey and defend themselves against predators. For this purpose, scorpion venom is composed of a variety of biologically active peptides (Ahmadi et al., 2020). Among them, neurotoxins are the most effective components in capturing their prey, such as insects. These toxins can immediately stop the movement of prey by acting on their ion channels (Schwartz et al., 2012, Smith, J. J. et al., 2013). In addition, these neurotoxins often show selective toxicity between insects and mammals, which is conferred at the ion channel level (Gordon et al., 2007, Housley et al., 2017).

Scorpion toxins acting on ion channels are peptides cross-linked with multiple disulfide bonds (Quintero-Hernandez et al., 2013). These peptides can be classified into two groups based on their molecular size. The long-chain group consists of peptides with 60-80 amino acid residues, which include toxins that act on $\mathrm{Na}^{+}$channels. The short-chain group consists of peptides with 20-50 amino acid residues, which include toxins that act on $\mathrm{K}^{+}, \mathrm{Ca}^{2+}$, and $\mathrm{Cl}^{-}$channels. The scorpion venom also contains many peptides without disulfide bonds. Most of these peptides show antimicrobial activity (Almaaytah and Albalas, 2014), some of which also exhibit insecticidal activity and/or synergistically enhance the activity of other toxins (Miyashita et al., 2010, Wullschleger et al., 2005). In addition to peptides, enzyme proteins are present in the scorpion venom, although their contribution to the biological activity of the venom remains unclear (Smith, J.J. and Alewood, 2015). Because of these diverse components, scorpion venom has been studied as a rich source of bioactive molecules, which provide useful information for the development of novel pesticides and drugs (Ghosh et al., 2019, Smith, J. J., et al., 2013). Scorpion toxins can also serve as an important probe for the study of ion channels (Herzig et al., 2020, Zhao, Y. et al., 2019).

Traditionally, the search for bioactive peptides/proteins has been conducted mainly relying on the bioassay-guided isolation procedure, in which high performance liquid chromatography (HPLC) fractionation and bioassay is repeated until a single active 
component is obtained (Vetter et al., 2011). This approach has led to the discovery of a number of novel bioactive molecules with unique structures. However, it is often difficult to identify minor components in the venom using this approach. In such cases, cDNAs obtained by reverse transcription of the mRNAs in the venom gland have been amplified by polymerase chain reaction (PCR) using a primer constructed based on a partial sequence to determine the entire structure (Quintero-Hernandez et al., 2011). Recently, the advent of next-generation high-throughput sequencing technologies allows us to obtain sequences of all mRNAs expressed in the venom gland (transcriptome), which provides a comprehensive understanding of structures of venom components (Oldrati et al., 2016). Furthermore, the combination of transcriptome analysis with proteome analysis has accelerated the determination of mature structures of each component in the venom (Fu et al., 2018, Walker et al., 2020). Although bioactive components can be estimated based on their structurally similarity with reported molecules using this approach, biological functions of many components remain unclear due to the absence of similar molecules reported. In this regard, the classical bioassay-guided approach is still effective for the discovery of bioactive components with unique structural characteristics, and its combination with transcriptome analysis should accelerate the structural determination.

It is known that infection with hepatitis $\mathrm{C}$ virus (HCV) often causes liver disease, including cirrhosis and hepatocellular carcinoma. Although highly effective direct-acting antivirals can cure the vast majority of $\mathrm{HCV}$ infections, in the absence of a vaccine, there is a continued demand for antiviral drugs against HCV. Of the various enemies and pathogens scorpions cope with, virus represents one of major threats, and actually the scorpion venom contains antiviral components to prevent infection via venom glands (da Mata et al., 2017, El-Bitar et al., 2015, Yacoub et al., 2020). In this context, the scorpion venom has been studied as one of the promising sources of antiviral molecules. Previously, we identified three insecticidal peptides from the venom of the Liocheles australasiae scorpion based on toxicity against insects (Juichi et al., 2019, Matsushita et al., 2009, 
100 Matsushita et al., 2007). However, the venom has not been evaluated for other biological activities, including antiviral effects. Thus, in this study, we first performed a transcriptome analysis of the venom gland of $L$. australasiae to gain a comprehensive understanding of its venom components. Using this information coupled with the bioassay-guided approach, we identified a new component with antiviral activity against HCV from the venom of L. australasiae.

\section{Materials and methods}

\subsection{Biological materials}

The scorpions L. australasiae were collected in Ishigaki Island, located at the southern end of the Ryukyu Islands in Japan. They were reared in the laboratory under humid conditions at $25^{\circ} \mathrm{C}$ and fed crickets. The venom was obtained by mechanical stimulation as previously reported (Miyashita et al., 2007). The venom secreted on Parafilm was dissolved in aqueous $2 \%$ acetic acid and filtered, which was lyophilized and stored at $80^{\circ} \mathrm{C}$.

\subsection{RNA extraction and sequencing}

The telsons were dissected from six specimens anesthetized on ice and placed in a glass tube of a micro tissue grinder. The total RNA was extracted using RNAiso Plus (Takara Bio, Kusatsu, Japan) and further purified using the RNeasy Mini Kit (Qiagen, Venlo, The Netherlands) according to the manufacturer's instructions. The integrity of the RNA was verified using a Bioanalyzer 2100 (Agilent Technologies, Santa Clara, CA, USA). The mRNA was isolated using the NEBNext Poly(A) mRNA Magnetic Isolation Module (New England Biolabs, Ipswich, MA, USA). A cDNA library was prepared from the purified mRNA using the NEBNext Ultra RNA Library Prep Kit for Illumina (New England Biolabs). The $100 \mathrm{bp}$ paired-end sequencing was performed on an Illumina HiSeq2500 platform (San Diego, CA, USA). The short-read data were deposited to the Read Archive of DDBJ (accession number DRA010798). 


\subsection{De novo assembly and functional annotations}

After adapter- and quality-trimming using the software TagDust (Lassmann et al., 2009) and Fastx-Toolkit (http://hannonlab.cshl.edu/fastx_toolkit), the cleaned reads were assembled into contigs with Trinity (2.06) (Haas et al., 2013) and Bridger (r2014-12-01) (Chang et al., 2015) software using the standard protocol. Coding regions were predicted by TransDecoder (2.0). The predicted sequences obtained using two different assembly software were separately submitted to similarity searches using the BLASTP program against a database containing only sequences identified from scorpion venom (the UniProt Animal Toxin Annotation Project) to annotate the functions of identified peptides and proteins through the local BLAST tool (Altschul et al., 1990). Coding regions of each component were further inspected and corrected manually by comparing them with the reported sequences. Multiple sequence alignments were performed using MAFFT online (Katoh et al., 2019) and Clustal Omega (Madeira et al., 2019).

\subsection{HPLC purification}

The crude venom dissolved in distilled water was applied to a $\mathrm{C} 4$ semi-preparative column $(10 \times 250 \mathrm{~mm}$, Grace Vydac, Deerfield, IL, USA). The column was eluted with $0.1 \%$ trifluoro acetic acid (TFA) in water (solvent A) and $0.08 \%$ TFA in acetonitrile (solvent B) at a flow rate of $2 \mathrm{~mL} / \mathrm{min}$, using a linear gradient of $5-60 \%$ of solvent B over $55 \mathrm{~min}$. Elution was monitored by the UV absorbance at $215 \mathrm{~nm}$. Fractions were collected every 5 min during gradient elution. Each fraction was submitted to the antiviral activity test after lyophilization, and the fraction showing activity was then applied to a C18 microbore column $(1.0 \times 250 \mathrm{~mm}$, Grace Vydac). The column was eluted with solvent A and B at a flow rate of $0.05 \mathrm{~mL} / \mathrm{min}$, using a linear gradient of $20-50 \%$ of solvent B over 60 min. Each HPLC peak was individually collected and lyophilized. The most active fraction was further purified on the same $\mathrm{C} 18$ microbore column using a different solvent system. The column was eluted with $0.1 \%$ formic acid in water (solvent $\mathrm{C}$ ) and $0.1 \%$ 
156 formic acid in acetonitrile (solvent D) at a flow rate of $0.05 \mathrm{~mL} / \mathrm{min}$ using a linear gradient of 5-55\% solvent D over $50 \mathrm{~min}$. The purity was checked by liquid chromatography/mass spectrometry (LC/MS) analysis as described below.

\subsection{Mass spectrometric analysis}

LC/MS and LC/MS/MS measurements were carried out in a positive ion mode on an LCMS-IT-TOF mass spectrometer (Shimadzu, Kyoto, Japan) equipped with an electrospray ion source. Precursor ions were manually selected, and a collision-induced dissociation (CID) spectrum was obtained by using argon as a collision gas. Reversedphase (RP)-HPLC separation was performed on a C18 microbore column (TSKgel ODS100V $3 \mu \mathrm{m}, 1.0 \times 150 \mathrm{~mm}$, Tosoh, Tokyo, Japan). The column was eluted with solvent $\mathrm{C}$ and solvent $\mathrm{D}$ at a flow rate of $0.05 \mathrm{~mL} / \mathrm{min}$, using a linear gradient of 5-70\% of solvent D over $65 \mathrm{~min}$. The mass scale was calibrated externally using sodium trifluoroacetate cluster ions.

\subsection{Enzymatic digestion}

The protein was dissolved in a buffer containing $0.2 \mathrm{M}$ Tris- $\mathrm{HCl}(\mathrm{pH} 8.5), 6 \mathrm{M}$ guanidine hydrochloride and $10 \mathrm{mM}$ dithiothreitol (DTT), and the mixture was incubated at $50^{\circ} \mathrm{C}$ for $1 \mathrm{~h}$. The reaction mixture was then mixed with iodoacetic acid (20 mM final concentration) and incubated at $28^{\circ} \mathrm{C}$ for $1 \mathrm{~h}$. The solution was diluted three-fold with water, and the Cys-alkylated protein was digested with endoproteinase Lys-C (FUJIFILM Wako Pure Chemical Corporation, Osaka, Japan) or Glu-C (FUJIFILM Wako Pure Chemical Corporation) at $37^{\circ} \mathrm{C}$ for $18 \mathrm{~h}$ at a peptide/enzyme ratio of $20: 1(\mathrm{w} / \mathrm{w})$.

\subsection{Deglycosylation}

The protein was dissolved in a solution containing $0.5 \%$ SDS and $40 \mathrm{mM}$ DTT, and the mixture was incubated at $100^{\circ} \mathrm{C}$ for $10 \mathrm{~min}$. The solution was diluted two-fold with a buffer containing $50 \mathrm{mM}$ sodium acetate and 1\% NP-20, then mixed with 5 units of 
PNGase A (New England Biolabs, Ipswich, MA, USA) at $37^{\circ} \mathrm{C}$ for $1 \mathrm{~h}$.

\subsection{Cell culture and viruses}

Huh7it-1 cells were cultivated in Dulbecco's modified Eagle's medium (FUJIFILM Wako Pure Chemical Corporation, Osaka, Japan) supplemented with fetal bovine serum (Biowest, Nuaille, France), non-essential amino acids (Thermo Fisher Scientific, Waltham, MA, USA), penicillin (100 IU/ml) and streptomycin $(100 \mu \mathrm{g} / \mathrm{ml})($ Thermo Fisher Scientific). Cells were grown at $37^{\circ} \mathrm{C}$ in a $5 \% \mathrm{CO}_{2}$ incubator. The J6/JFH1-P47 strain of HCV (El-Bitar, et al., 2015), the Trinidad 1751 strain of dengue virus (DENV) (El-Bitar, et al., 2015), the Nakayama strain of Japanese encephalitis virus (JEV) (Song et al., 1999), and the CHR3 strain of herpes simplex virus type 1 (HSV-1) (Aoki-Utsubo et al., 2018) prepared in Huh7it-1 cells were used in this study. Infectivity of the stock virus was $1.5 \times 10^{6}, 9.0 \times 10^{5}, 5.0 \times 10^{5}$, and $2.0 \times 10^{4}$ cell-infecting units (CIU)/ml for HCV, DENV, JEV and HSV-1, respectively.

\subsection{Antiviral activity test}

Antiviral activity was tested according to two different experimental procedures as described below.

(i) Pretreatment of virus with venom components before and during virus inoculation (pretreatment). This procedure is used to determine virucidal (neutralizing) activity of a test sample (Aoki-Utsubo, et al., 2018, El-Bitar, et al., 2015). In brief, Huh7it-1 cells were seeded in 24-well plates $\left(1.6 \times 10^{5}\right.$ cells/well). A fixed amount of the virus (either 10-fold diluted or undiluted stock virus) was mixed with serial dilutions of the whole venom or separated HPLC fractions of the venom and inoculated to the cells for $2 \mathrm{~h}$. The cells were then washed with medium to remove the residual virus and venom components, and further cultured in medium. Culture supernatants were obtained at 24-48 h post-infection and titrated for virus infectivity as described previously (El-Bitar, et al., 2015). After 24 $\mathrm{h}$, the virus-infected cells were washed with phosphate-buffered saline (PBS), fixed with 
$2124 \%$ paraformaldehyde for 20 min, and permeabilized with $0.1 \%$ Triton X-100 in PBS for

$21315 \mathrm{~min}$ at room temperature. After being washed three times with PBS, the cells were

214 incubated with UV-inactivated $\mathrm{HCV}$-infected patient's serum for $1 \mathrm{~h}$, followed by 215 incubation with FITC-conjugated goat anti-human IgG (Medical \& Biological

216 Laboratories Co., Ltd., Nagoya, Japan). The cells were counterstained with Hoechst 21733342 (Molecular Probes, Eugene, OR, USA) for $5 \mathrm{~min}$, and HCV-infected cells were 218 counted under a BX53LED-43FLD fluorescence microscope (Olympus Corporation, 219 Tokyo, Japan). Virus and cells treated with medium served as controls. Percent inhibition 220 of virus infectivity by the samples was calculated by comparing with the controls, and $50 \%$ inhibitory concentrations $\left(\mathrm{IC}_{50}\right)$ were determined. Experiments were performed in duplicate and repeated three times.

(ii) Treatment of virus-infected cells after virus has been entered the cells (post-entry treatment). This procedure is used to determine viral replication-inhibiting activity of a test sample in the infected cells (Aoki-Utsubo, et al., 2018, El-Bitar, et al., 2015) In brief, cells were inoculated with virus in the absence of the venom components for $2 \mathrm{~h}$. The virus-infected cells were cultured in medium containing serial dilutions of the venom components. The virus-infected cells cultured in medium without the venom components served as a control. After $48 \mathrm{~h}$, RNA was extracted from the cells and subjected to reverse transcription-quantitative PCR (RT-qPCR) as described below. Experiments were performed in duplicate and repeated three times.

\subsection{Reverse transcription-quantitative PCR (RT-qPCR)}

Total cellular RNA was extracted from the cells using NucleoSpin RNA extraction kit (TaKaRa Bio, Inc.) according to the manufacturer's instructions. RNA $(1 \mu \mathrm{g})$ was reverse transcribed using a GoScript Reverse Transcription system (Promega) with random primers. The cDNA products were subjected to quantitative real-time PCR analysis using Power SYBR Green PCR Master kit (Thermo Fisher Scientific Corp.) and a StepOne qPCR system (Thermo Fisher). The primers used to amplify an NS5A region of the HCV 
240 genome were 5'-AGACGTATTGAGGTCCATGC-3' (sense) and 5'-

CCGCAGCGACGGTGCTGATAG-3' (antisense) (Deng, L. et al., 2011). As an internal control, human glyceraldehyde-3-phosphate dehydrogenase (GAPDH) gene expression levels were measured using primers 5'-GCCATCAATGACCCCTTCATT-3' (sense) and 5' TCTCGCTCCTGGAAGATGG-3'. Relative quantity of HCV NS5A cDNA was calculated and expressed as an arbitrary unit for each sample.

\subsection{Cytotoxicity test}

Cytotoxicity of LaPLA $2-1$ was evaluated using the WST-1 reagent (Roche, Mannheim, Germany) as reported previously (El-Bitar, et al., 2015). Briefly, Huh7it-1 cells plated in each well of a 96 -well plate $(0.1 \mathrm{ml} /$ well $)$ were treated with serial dilutions $(0.1$ to 1,000 $\mathrm{ng} / \mathrm{ml}$ ) of LaPLA $2-1$ at $37{ }^{\circ} \mathrm{C}$ for $24 \mathrm{~h}$. Untreated cells served as a control. After this treatment, $10 \mu \mathrm{l}$ of the WST-1 reagent was added to each well, and the cells were cultured for $4 \mathrm{~h}$. The WST-1 reagent is converted to formazan by living cells. The amount of formazan, which correlates with the number of living cells, was determined by measuring the absorbance at 450 and $630 \mathrm{~nm}$ using a microplate reader. The percent cell viability compared to the untreated control was calculated, and the $50 \%$ cytotoxic concentration $\left(\mathrm{CC}_{50}\right)$ was determined.

\subsection{Phospholipase $A_{2}$ activity test}

L- $\alpha$-Phosphatidylcholine (from egg yolk, Nacalai Tesque, Kyoto, Japan) was suspended in a buffer containing $0.1 \mathrm{M}$ Tris- $\mathrm{HCl}(\mathrm{pH} 8.0), 10 \mathrm{mM} \mathrm{CaCl}_{2}$, and $0.2 \%$ TritonX-100 at a concentration of $2 \mathrm{mg} / \mathrm{ml}$. The reaction was started with the addition of the $\mathrm{PLA}_{2}$ solution to the buffer (total $100 \mu \mathrm{l}$ ) at $37^{\circ} \mathrm{C}$. After incubation for $10 \mathrm{~min}$ at $37^{\circ} \mathrm{C}$, the mixture was analyzed by LC/MS to quantitate the amount of 1-palmitoyl-sn-glycero3-phosphocholine (P-lysoPC, $m / z$ 540.3, $[\mathrm{M}+\mathrm{HCOOH}-\mathrm{H}]^{-}$) generated by the reaction.

266 Conditions used for LC/MS analysis (LCMS-8030, Shimadzu) were as follows: ionization, ESI-negative; column, COSMOCORE 2.6C 18 (2.1×75 mm, Nacalai Tesque); 
flow rate, $0.3 \mathrm{~mL} / \mathrm{min}$; mobile phase, solvent $\mathrm{C}$ and solvent $\mathrm{D}$; gradient, $35-95 \%$ of solvent D over $30 \mathrm{~min}$. The amount of P-lysoPC generated in the absence of phospholipase $\mathrm{A}_{2}\left(\mathrm{PLA}_{2}\right)$ was subtracted from those generated in each experiment. Experiments were repeated three times. PLA 2 activity was expressed relative to that of $\mathrm{PLA}_{2}$ from honeybee (Apis mellifera) venom (Sigma-Aldrich, St. Louis, MO, USA).

\section{Results}

\subsection{Transcriptome analysis}

A total of 253,691,496 raw reads were obtained by sequencing. After adapter- and quality-trimming, the clean reads were assembled in a de novo fashion using Trinity, which resulted in 133,715 contigs with N50 of 849 bp (224-14,739 bp), and Bridger software, which resulted in 98,577 contigs with N50 of 1447 bp (201-21,016 bp). BLASTP search was performed for predicted coding regions against a database consisting of reported sequences identified from scorpion venom. This resulted in identification of 77 transcripts encoding peptides and proteins similar to those of scorpion venom as shown in Fig. 1-5 and Table S1 and S2.

\subsection{Components identified by venom gland transcriptome analysis}

\subsubsection{Non-disulfide bridged peptides}

Scorpion venoms are rich in non-disulfide bridged peptides (NDBPs) (Almaaytah and Albalas, 2014). NDBPs are known to display diverse biological functions to defend from pathogen infection via the venom gland by showing antimicrobial activity and/or to capture prey by showing insecticidal activities (Almaaytah and Albalas, 2014, Dias et al., 2018, Miyashita, et al., 2010). NDBPs are classified into five subfamilies based on the sequence similarity and the molecular size. In this study, we identified nine transcripts coding for NDBPs (Fig. 2a); two transcripts (LaNDBP2-1 and LaNDBP2-2) sharing sequence similarity to those of group 2 consisting of long-chain multifunctional peptides, two transcripts (LaNDBP3-1 and LaNDBP3-2) to those of group 3 consisting of medium- 
296 length antimicrobial peptides, and five transcripts (LaNDBP4-1, LaNDBP4-2, 297 LaNDBP4-3, LaNDBP4-4, and LaNDBP4-5) to those of group 4 consisting of short 298 antimicrobial peptides.

\section{$\underline{\text { 3.2.2. Invertebrate defensins }}$}

Defensins are cationic peptides stabilized with three disulfide bonds, which are observed in a wide variety of organisms, including plants, insects, and mammals (Holly et al., 2017, Yi et al., 2014). These peptides play an important role in innate immunity by showing antimicrobial activity. Peptides similar to defensins are also found in scorpion venom (Cheng et al., 2020, Harrison et al., 2014, Meng et al., 2016). Although a limited number of scorpion venom peptides were reported as a defensin, a similar structural motif exists in potassium channel toxins as described below (Zhu, S. Y. et al., 2014). In this study, we found three transcripts (LaDefensin1, LaDefensin2, and LaDefensin3) coding for invertebrate defensins, which share sequence similarity to AbDef-1 that was identified from the venom of Androctonus bicolor (Fig. 2b) (Zhang et al., 2015).

\subsubsection{Potassium channel toxin-like peptides}

Potassium channel toxins (KTx) are cysteine-rich peptides that act on potassium channels (Jimenez-Vargas et al., 2017). To date, a large number of KTx peptides have been identified from scorpion venom. KTx peptides are currently classified into seven groups $\left(\alpha-, \beta-, \gamma-, \delta-, \varepsilon_{-}^{-}, \kappa-\right.$, and $\left.\lambda-\mathrm{KTx}\right)$ based on the sequence similarity and disulfidebonding patterns (Chen, Z. Y. et al., 2012, Jimenez-Vargas, et al., 2017). In this study, we identified 18 transcripts coding for KTx peptides, and the majority of them were $\alpha-\mathrm{KTx}$ peptides (La-alphaKTx1, La-alphaKTx2, La-alphaKTx3, La-alphaKTx4, La-alphaKTx5, La-alphaKTx6, La-alphaKTx7, La-alphaKTx8, and La-alphaKTx9, Fig. 3a). $\alpha$-KTx adopts a typical fold consisting of an $\alpha$-helix and three $\beta$-strands stabilized by three or four disulfide bonds (CS- $\alpha \beta$ fold). We also found three transcripts (La-betaKTx1, LabetaKTx2, and La-betaKTx3) coding for $\beta$-KTx peptides (Fig. 3b). These peptides adopt 
a CS- $\alpha \beta$ fold as observed in $\alpha-\mathrm{KTx}$ peptides, but they have an additional $\alpha$-helical structure without disulfide bonds at the N-terminal region. La-betaKTx1 and LabetaKTx2 correspond to LaIT2 and LaIT3, which were previously identified from the $L$. australasiae venom at a peptide level, respectively (Juichi, et al., 2019, Matsushita, et al., 2009). Five transcripts (La-kappaKTx1, La-kappaKTx2, La-kappaKTx3, La-kappaKTx4, and La-kappaKTx5) coding for $\kappa-K T x$ peptides were also found (Fig. 3c). Unlike $\alpha$ - and $\beta$-KTx peptides, $\kappa-K T x$ peptides do not adopt a CS- $\alpha \beta$ fold, but instead they have two parallel $\alpha$-helices stabilized with two disulfide bonds. The inhibitory activity of $\kappa-\mathrm{KTx}$ on potassium channels is known to be relatively weak compared with that of $\alpha-\mathrm{KTx}$ peptides. Furthermore, one transcript (La-deltaKTx1) coding for $\delta$-KTx was identified, which has a similar structure with Kunitz-type protease inhibitors consisting of two antiparallel $\beta$-strands and an $\alpha$-helix stabilized by three or four disulfide bonds (Fig. 3d). Some $\delta$-KTx peptides, such as BmKTT-2 from the Mesobuthus martensii venom, are known to show inhibitory activity on both potassium channels and proteases (Chen, Z. Y., et al., 2012).

\subsubsection{Disulfide-directed hairpin peptides}

Peptides with disulfide-directed hairpin (DDH) motif were identified from the venom of the limited number of scorpion species (Horita et al., 2011, Smith, J. J. et al., 2011). Although DDH peptides contain only two disulfide bonds, their structures are similar to the inhibitory cystine knot (ICK) motif, which is stabilized by three disulfide bonds. LaIT1, an insecticidal peptide previously identified from the venom of L. australasiae, is the first example of DDH peptides (Matsushita, et al., 2007). In this study, two transcripts (LaDDH1 and LaDDH2) coding for DDH peptides were identified, in which LaDDH1 corresponds to LaIT1 (Fig. 4a).

\subsubsection{Sodium channel toxin-like peptides}

Sodium channel toxins (NaTxs) adopt a CS- $\alpha \beta$ fold as observed in $\alpha$-KTx peptides, 
but their sequences are relatively long (58-76 residues) (Housley, et al., 2017, QuinteroHernandez, et al., 2013). NaTx peptides were identified mainly from the venom of Buthidae scorpions, and their sodium channel modulating activity is thought to be responsible for the relatively high toxicity of Buthidae scorpion venom (Cid-Uribe et al., 2019, de Oliveira et al., 2015, Luna-Ramirez, K. et al., 2015, Ward et al., 2018, Zhao, R. M. et al., 2010, Zhong et al., 2017). In addition to ion channel modulating activity, several members of this family are known to induce adipocyte lipolysis by forming a homodimer (Soudani et al., 2005, Zhu, S. and Gao, 2006). In the present study, two transcripts (LaLAP1 and LaLAP2) coding for the peptides similar to lipolysis-activating peptides were identified (Fig. 4b). However, these peptides could have other biological functions because the total number or the position of Cys residues are different from those of the known lipolysis-activating peptides (Zhu, S. and Gao, 2006).

\subsubsection{Serine protease inhibitor-like peptides}

Animal venom generally contains protease inhibitors probably for protecting the venom components from enzymatic degradation. Two types of inhibitors having different structural motifs (Kunitz- and Ascaris-type) are known to exist in scorpion venom (Chen, Z. Y. et al., 2013, Ranasinghe and McManus, 2013). In this study, we found one transcript (La-deltaKTx1) coding for Kunitz-type inhibitor-like peptides, which was classified as $\delta$ KTx peptides as described above (Fig. 3d). In addition, we found eight transcripts (LaAPI1, LaAPI2, LaAPI3, LaAPI4, LaAPI5, LaAPI6, LaAPI7, and LaAPI8) coding for Ascaris-type inhibitor-like peptides (Fig. 4c). Interestingly, LaAPI1 contains only eight Cys residues that can form four disulfide bonds, whereas a typical Ascaris-type motif is stabilized by five disulfide bonds.

\subsubsection{La1-like peptides}

La1 was previously identified as the most abundant peptide in the L. australasiae venom (Miyashita, et al., 2007). To date, peptides similar to Lal have been identified 
380 from the venom of diverse scorpion species, although their biological significance remains unknown. La1-like peptides adopt a single domain von Willebrand factor type C (SVWC) motif (Sheldon et al., 2007). Some peptides adopting this motif based on the position of Cys residues are classified as SVWC peptides. In the present study, we identified eight transcripts (La1, La1-1, La1-2, La1-3, La1-4, La1-5, La1-6, and La1-7) coding for La1-like or SVWC peptides (Fig. 5).

\subsubsection{Enzymes}

In scorpion venom, enzymes have not been recognized as major bioactive components. However, recent progress in venom gland transcriptome analysis revealed that there are various enzymes, such as phospholipase, metalloprotease, serine protease, and hyaluronidase, in the venom (Bordon et al., 2015, Carmo et al., 2014, Gao, R. et al., 2008, Krayem and Gargouri, 2020). In this study, we identified three transcripts (LaPLA $2-1$, $\mathrm{LaPLA}_{2}-2$, and $\mathrm{LaPLA}_{2}-3$ ) coding for phospholipase $\mathrm{A}_{2}$, and eight transcripts (LaSP1, LaSP2, LaSP3, LaSP4, LaSP5, LaSP6, LaSP7, and LaSP8) coding for serine protease (Table S2). In addition to these enzymes, we identified one transcript (La-alpha-amylase) coding for $\alpha$-amylase. Since only a limited number of $\alpha$-amylase sequences have been identified from scorpion venom at a transcript level, there is little information on their biological functions.

\subsubsection{Other proteins}

We identified 10 transcripts (LaCRVP1, LaCRVP2, LaCRVP3, LaCRVP4, LaCRVP5, LaCRVP6, LaCRVP7, LaCRVP8, LaCRVP9, and LaCRVP10) coding for cysteine-rich secretory proteins, and three transcripts (LaVP1, LaVP2, and LaVP3) coding for proteins with an insulin-like growth factor binding motif (Table S2). Although these proteins are widely observed in scorpion venom, their biological functions remain unknown (Amorim et al., 2019, de Oliveira, et al., 2015, Yang et al., 2014). 


\subsection{Isolation of an anti-HCV component}

We first evaluated anti-HCV activity of the venom of $L$. australasiae. The result showed that the venom has a significant inhibitory activity against $\mathrm{HCV}$ infection at extremely low concentrations $\left(\mathrm{IC}_{50}=0.01 \mu \mathrm{g} / \mathrm{ml}\right.$ ). To isolate a component responsible for the anti-HCV activity, the venom was separated using RP-HPLC on a C4 column (Fig. 6a). Each fraction was tested for anti-HCV activity, and the fraction eluting at 37-42 min was found to be active. This fraction was further separated using a C18 column (Fig. 6b). The HPLC peak eluting at 25.5-26.5 min showed the most significant activity, and the main component in this peak was found to be responsible for anti-HCV activity (Fig. 6c). Mass spectrometric analysis revealed the molecular mass of this component as 13,079.8 Da.

\subsection{Structure determination of the anti-HCV component}

The anti-HCV component was subjected to reduction and alkylation reactions to examine the number of disulfide bonds in this molecule. LC/MS analysis showed that the molecule was separated into two parts after the reactions, indicating that the anti-HCV component consists of two subunits cross-linked with disulfide bonds (Fig. 7a). Molecular masses of each subunit after alkylation of Cys residues were determined as 1145.2 $\mathrm{Da}$ (small subunit) and 12,524.7 $\mathrm{Da}$ (large subunit). A total increase of the molecular mass after Cys-alkylation was approximately 590 Da [(1145.2 + 12,524.7) $13,079.8=590 \cdot 1]$. Considering a mass shift due to carboxymethylation of Cys residues (118 Da per disulfide bond), we determined that the anti-HCV component contains five disulfide bonds $(118 \times 5=590)$.

To obtain partial sequence information from the anti-HCV component, MS/MS de novo sequencing analysis was performed for the small subunit. As shown in Fig. 7b, the sequence of the small subunit was determined as KCVAHWKES. This sequence was searched from all transcripts obtained in this study, and the anti-HCV component was identified as $\mathrm{LaPLA}_{2}-1$, one of the phospholipase $\mathrm{A}_{2}$ proteins. As observed in other 
scorpion $\mathrm{PLA}_{2} \mathrm{~S}, \mathrm{LaPLA}_{2}-1$ forms a heterodimeric structure through processing. However, a sequence region that corresponds to the large subunit could not be determined based on its observed molecular mass $(12,524.7 \mathrm{Da})$. It was assumed that the large subunit undergoes some types of post-translational modifications (PTMs). To determine a mature structure of the large subunit of LaPLA $2-1$ including PTMs, it was digested with Lys-C or Glu-C, which was analyzed by LC/MS (Table 1). The N- and C-terminal sites of the large subunit were identified based on the sequences of two Lys-C digests (LIFPGTK and CFVLDCD), because these peptides cannot be generated by Lys-C digestion (IHQR/LIFPG- and -VLDCD/KRRF-). The calculated molecular mass of the deduced sequence of the large subunit is $11,826.2 \mathrm{Da}$, which is still $698.5 \mathrm{Da}$ lower than the measured value $(12,524.7 \mathrm{Da})$. When the LC/MS data of Lys-C and Glu-C digests were carefully examined, the molecular masses of two digested peptides (AANYSDLGSAAETDK and LIFPGTKWCGAGDKAANYSDLGSAAE) were found to be $698 \mathrm{Da}$ higher than those calculated without modifications. These peptides share the same sequence region containing an N-linked glycosylation consensus motif (NXS) (Marshall, 1972). This suggests that the Asn residue in this region is glycosylated. To confirm the existence of an N-linked glycan at this position, the protein was treated with PNGase A, which can cleave the N-glycan moiety from the Asn residue (Plummer and Tarentino, 1981). LC/MS analysis showed that the measured molecular mass of the large subunit after removal of N-glycan was identical to the calculated one (11,304.9 Da, Fig. $\mathrm{S} 1)$. The large subunit without $\mathrm{N}$-glycan was then treated with Lys-C after reduction and alkylation of Cys residues. The existence of the peptide containing an Asp residue instead of the N-glycosylated Asn residue was confirmed by LC/MS analysis (Table 1). To obtain structural information of the N-glycan moiety, MS/MS analysis was performed for the Lys-C digested peptide containing the N-glycan moiety. As shown in Fig. 8, several fragment ions formed through regular and successive losses of 203 and $145 \mathrm{Da}$, which correspond to an $\mathrm{N}$-acetyl hexose and a deoxyhexose, respectively, were observed in the product ion spectrum. Based on the fragmentation pattern and the molecular masses, the 
464 N-glycan moiety is supposed to consist of two N-acetyl hexoses and two deoxyhexoses. Considering the N-glycan structures and the biosynthetic pathways reported for arthropods including scorpions and insects (Hassani et al., 1999, Staudacher et al., 1992, Walski et al., 2017), the N-glycan structure in LaPLA $2-1$ was estimated as shown in Fig. 8. Homology searches revealed that $\mathrm{LaPLA}_{2}-1$ shares high sequence similarity to hemilipin from Hemiscorpius lepturus, HgPLA2 from Hadrurus gertschi, and phaiodactylipin from Anuroctonus phaiodactylus (Fig. 9) (Jridi et al., 2015, Schwartz et al., 2007, Valdez-Cruz et al., 2004).

\subsection{Antiviral activity of LaPLA $A_{2}-1$}

LaPLA $_{2}-1$ inhibited infectivity of $\mathrm{HCV}$ in a concentration-dependent manner from 0.1 to $100 \mathrm{ng} / \mathrm{ml}$ (Fig. 10). Antiviral activity of LaPLA2-1 against several viruses was further examined. Accordingly, $\mathrm{IC}_{50}$ values of $\mathrm{LaPLA}_{2}-1$ against $\mathrm{HCV}$, DENV and JEV, which belong to the family Flaviviridae, were 2.0, 3.4 and $5.7 \mathrm{ng} / \mathrm{ml}$, respectively (Table 2). On the other hand, LaPLA 2 -1 did not exhibit virucidal activity against HSV-1, which belongs to the family Herpesviridae even at a much higher concentration $(1,000 \mathrm{ng} / \mathrm{ml})$ (Fig. 10 and Table 2). To determine whether the post-entry step of the viral life cycle is affected by LaPLA $2-1$, possible effect of post-entry treatment with LaPLA2-1 on virus replication in infected cells was examined. The result demonstrated that post-entry treatment with LaPLA $_{2}-1$ barely exhibited anti-HCV activity even at a high concentration $(100 \mathrm{ng} / \mathrm{ml})$, whereas pretreatment exhibited highly potent anti-HCV activity (Table S3).

To examine whether the virucidal activity of $\mathrm{LaPLA}_{2}-1$ against $\mathrm{HCV}$ is associated with its enzymatic activity, the effect of $\mathrm{PLA}_{2}$ inhibitor on the anti-HCV activity was evaluated. The result obtained revealed a dramatic decrease of the virucidal activity in the presence of manoalide, the $\mathrm{PLA}_{2}$ inhibitor (Lombardo and Dennis, 1985). In addition, LaPLA $2-1$ exhibited the significant phospholipase activity at a comparable level that was observed for bee venom PLA 2 (Fig. 11). These results suggest that the virucidal activity of LaPLA21 against $\mathrm{HCV}$ is closely associated with its enzymatic activity. In the present study, the 
concentration ranges of $\mathrm{LaPLA}_{2}-1$ that showed virucidal and $\mathrm{PLA}_{2}$ activities appear to be different. However, this may be due to differences in states of the substrate (membrane versus solution) and incubation time used for measurements ( $2 \mathrm{~h}$ versus $10 \mathrm{~min}$ ) between virucidal and $\mathrm{PLA}_{2}$ activity tests.

We also evaluated the toxicity of $\mathrm{LaPLA}_{2}-1$ to the host cells. $\mathrm{LaPLA}_{2}-1$ showed no cytotoxic effect at concentrations of up to $100 \mathrm{ng} / \mathrm{ml}$ and only a marginal cytotoxic effect at $1,000 \mathrm{ng} / \mathrm{ml}$ (Table S4), suggesting that observed $\mathrm{LaPLA}_{2}-1$ action is specific to the viruses.

\section{Discussion}

\subsection{Peptides identified by venom gland transcriptome analysis}

Previously, we isolated and characterized four peptides (LaIT1, LaIT2, LaIT3, and La1) from the venom of the scorpion $L$. australasiae, mainly based on toxicity against insects (Juichi, et al., 2019, Matsushita, et al., 2009, Matsushita, et al., 2007, Miyashita, et al., 2007). In the present study, we performed the transcriptome analysis of the venom gland of $L$. australasiae to comprehensively understand the components in the venom. This resulted in the identification of 77 transcripts coding for peptides and proteins similar to those from the venom of other scorpion species. Among them, KTx-like peptides, including insecticidal toxins LaIT2 and LaIT3, were more diverse than other families of venom components (Fig. 1). On the other hand, only three NaTx-like peptides were identified in this study. This is consistent with the previous observations obtained by mass spectrometric analysis (Miyashita, et al., 2007). The number of the components with molecular masses of 6,000-9,000 $\mathrm{Da}$, which may correspond to NaTx-like peptides, detected at the peptide level was relatively small in the L. australasiae venom when compared with that observed in the Buthidae scorpion venom. On the other hand, the number of the components with molecular masses of 3,000-5,000 Da, which may correspond to KTx-like peptides, was relatively large at the peptide level. A similar trend was noted in the transcriptome analysis of the venom glands of Hadogenes troglodytes of 
the family Hormuridae (Zhong, et al., 2017). The study showed the existence of many KTx-like peptides in the venom, whereas no NaTx-like peptides were found. It is known that NaTx peptides have been found mainly from the venom of Buthidae scorpions (CidUribe, et al., 2019, de Oliveira, et al., 2015, Luna-Ramirez, K., et al., 2015, QuinteroHernandez, et al., 2013, Ward, et al., 2018, Zhao, R. M., et al., 2010, Zhong, et al., 2017). This suggests that sodium channels are not a main target of the venom components in non-Buthidae scorpions.

LaIT2 and LaIT3 belong to the $\beta$-KTx peptide group, which is structurally characterized by the $\alpha$-helical region attached to the N-terminal of a CS- $\alpha \beta$ fold. In addition to these toxins, we found another peptide having a structure similar to $\beta$-KTx peptides (Fig. 3b). This peptide (La-betaKTx3) has the sequence similar to scorpine-like peptides, such as SCl1 from Urodacus yaschenkoi, which are classified as one of the subfamilies of $\beta$-KTx peptides (Luna-Ramirez, Karen et al., 2016, Luna-Ramirez, K. et al., 2013). Since scorpine-like peptides are known to show antibacterial activity, LabetaKTx3 is likely to have a similar biological function.

LaIT1 is the first insecticidal toxin identified from the L. australasiae venom (Matsushita, et al., 2007). In the present study, another peptide (LaDDH2) that has the sequence similar to LaIT1 was found (Fig. 4a). Two basic residues (R13 and R15) that are important for the expression of the insecticidal activity of LaIT1 are conserved in LaDDH2, suggesting that this peptide may also have insecticidal activity (Horita, et al., 2011). To date, peptides similar to LaIT1 have been identified from the family Hormuridae (L. waigiensis and Opisthacanthus cayaporum) (Silva et al., 2009, Smith, J. J., et al., 2011) and the family Hemiscorpiidae (Hemiscorpius lepturus) (KazemiLomedasht et al., 2017). This suggests that LaIT1 and its related peptides have been evolved independently in limited scorpion species.

La1 was previously identified as the most abundant component in the L. australasiae venom, although its biological function remains unknown (Miyashita, et al., 2007). Unlike LaIT1, peptides similar to La1 have been found in a wide variety of scorpion 
species from seven families; Buthidae (Zeng et al., 2013, Zhao, R. M., et al., 2010), Hemiscorpiidae (Kazemi-Lomedasht, et al., 2017), Hormuridae (Silva, et al., 2009, Zhong, et al., 2017), Scorpionidae (Abdel-Rahman et al., 2013, Deng, Y. C. et al., 2018, Diego-Garcia et al., 2012, Luna-Ramirez, K., et al., 2015), Superstitioniidae (SantibanezLopez et al., 2016), and Vaejovidae (Quintero-Hernandez et al., 2015, Romero-Gutierrez et al., 2018). Particularly, many Lal-like peptides were observed in the venom gland transcriptome of H. troglodytes (Zhong, et al., 2017). Therefore, it is possible that La1like peptides are abundant in the venom of Hormuridae scorpions, as observed in this study (Fig. 5). Lal adopts an SVWC motif, which has been observed in peptides from a wide variety of arthropods, including insects (Sheldon, et al., 2007). Recently, it has been reported that SVWC peptides may play a role in protection against entomopathogenic fungi in the epidermis of the silkworm and in basal AMPs expression of bumblebee (Han et al., 2017, Wang et al., 2017). Although the mechanisms of action of these peptides are still unknown, La1 might play a role in preventing pathogenic infections in the venom glands as well.

In addition to the peptides having disulfide bonds, many NDBPs were identified in this study (Fig. 2a). These peptides generally show membrane-disrupting activity by forming an amphipathic $\alpha$-helical structure (Harrison, et al., 2014). Among five subfamilies of scorpion NDBPs, peptides of four subfamilies were found in this study. The reasons for the presence of the various types of NDBPs in the venom are unknown, but they are likely to have different biological functions. For example, four NDBPs isolated from Isometrus maculatus show different antimicrobial spectra, and some of them also exhibit insecticidal and hemolytic activities (Miyashita et al., 2017). Furthermore, some NDBPs may have a synergistic effect on other neurotoxins in venom to enhance their activity (Gao, B. et al., 2018). Defensins are another type of antimicrobial peptides observed in a wide variety of organisms (Holly, et al., 2017, Yi, et al., 2014). In this study, three defensin-like peptides were found (Fig. 2b). Since invertebrate defensins have the same disulfide-bonding pattern as peptides that act on potassium channels, it is 
also possible that defensins identified in this study could show some ion channelmodulating activity (Meng, et al., 2016).

A number of peptides similar to serine protease inhibitors were also found in the present study (Fig. 4c). Kunitz-type protease inhibitors have been found in many organisms (Mishra, 2020). The peptides having a Kunitz-type motif have been reported to be present in the venom of various scorpion species (Ranasinghe and McManus, 2013). In addition to Kunitz-type peptides, Ascaris-type protease inhibitors have also been identified from the scorpion venom (Chen, Z. Y., et al., 2013). These peptides are likely responsible for preventing degradation of venom components by proteases of its own or other organisms. In addition, some of the protease inhibitor peptides from scorpion venom are known to act on potassium channels. This is thought to be a result of divergent evolution. For example, BmKTT-2, a Kunitz-type peptide identified from Mesobuthus martensii, shows inhibitory activity on Kv1.3 channels as well as inhibition of trypsin activity (Chen, Z. Y., et al., 2012). Since La-deltaKTx1 identified in this study (Fig. 3d) shares sequence similarity to BmKTT-2, it could show potassium channel inhibition activity.

\subsection{Anti-HCV component in the $\mathrm{L}$. australasiae venom}

In the present study, we found that the L. australasiae venom has a potent virucidal activity against $\mathrm{HCV}$ and successfully identified $\mathrm{LaPLA}_{2}-1$ as an anti-HCV component in the venom using a bioassay-guided approach. PLA 2 enzymes can be found in a wide variety of organisms, including snake and bee venom (Dennis et al., 2011). They catalyze the hydrolysis of glycerophospholipids at the $s n-2$ position to release free fatty acids and lysophospholipids. PLA 2 molecules can be classified into six types, and scorpion venom $\mathrm{PLA}_{2}\left(\mathrm{scvPLA}_{2}\right)$ belongs to group III of secreted PLA 2 (sPLA ${ }_{2}$ ) (Krayem and Gargouri, 2020). This group also includes $\mathrm{PLA}_{2}$ from bee venom (bvPLA $\mathrm{A}_{2}$. Some of $\mathrm{sPLA}_{2}$ molecules are known to exhibit antiviral activity, and their enzymatic activity is suggested to be associated with antiviral activity (Chen, M. et al., 2017). For example, PLA 2 
molecules from snake venom ( $\mathrm{svLA}_{2}$ ) specifically act on Flaviviridae viruses. This is likely because they can degrade the viral envelope membranes, particularly those derived from endoplasmic reticulum (ER). In fact, $\mathrm{LaPLA}_{2}-1$ efficiently inhibited the infection of Flaviviridae viruses such as $\mathrm{HCV}, \mathrm{DENV}$ and $\mathrm{JEV}\left(\mathrm{IC}_{50}=2.0,3.4\right.$ and $5.7 \mathrm{ng} / \mathrm{ml}$, respectively). A comparable degree of virucidal activity was reported for PLA $2 \mathrm{~S}$ obtained from snake venom (Teixeira et al., 2020). However, no significant antiviral activity was observed for a Herpesviridae virus such as HSV-1, which has the plasma membrane (PM)-derived envelope. This suggests that $\mathrm{LaPLA}_{2}-1$ has the same mechanism of action as svPLA (Chen, M., et al., 2017). It has been shown that phaiodactylipin can hydrolyze phosphatidylcholine more preferably than phosphatidylethanolamine and phosphatidylserine (Valdez-Cruz, et al., 2004). Since the ER-budded viruses contain a relatively high proportion of phosphatidylcholine than PM-budded viruses (Callens et al., 2016), LaPLA 2 may have a similar substrate preference as observed for phaiodactylipin. The possible action specificity of $\mathrm{LaPLA}_{2}-1$ on the ER membrane implies that it may have no adverse effect on the host cells, which is further supported by its low cytotoxicity with $\mathrm{CC}_{50}$ being $>1,000 \mathrm{ng} / \mathrm{ml}$. Although $\mathrm{PLA}_{2} \mathrm{~s}$, in general, are known to be cytotoxic and inflammatory or neurotoxic, LaPLA $2-1$ or its derivative(s) might be a good candidate as a lead compound for the development of an antiviral drug against HCV, DENV and other viruses budding from the ER membranes.

It is known that the $\mathrm{Ca}^{2+}$-binding motif (XCGXG) and the catalytic center with a HisAsp dyad are important for the expression of enzyme activity of PLA 2 (Dennis, et al., 2011). In the structures of $\operatorname{scvPLA}_{2} \mathrm{~s}$, these motifs are conserved except for phaiodactylipin, in which one of the Gly residues in the $\mathrm{Ca}^{2+}$-binding motif is missing (Fig. 9). The structure of $\operatorname{scvPLA}_{2} \mathrm{~S}$ is further characterized by the formation of a heterodimer consisting of a large and a small subunit cross-linked with a disulfide bond, although its relevance to biological function remains unknown. It is also known that many bvPLA 2 s contain N-glycans, most of which are core-fucosylated (Kubelka et al., 1993). Glycosylation of scvPLA 2 molecules has been investigated particularly for 
phaiodactylipin (Valdez-Cruz, et al., 2004). Three N-glycosylation sites were recognized in the structure of phaiodactylipin, one of which is located at the N-terminal region of the large subunit, as observed in LaPLA 2 -1 (Fig. 9). Hemilipin, HgPLA 2 , and bvPLA 2 also contain one or two possible N-glycosylation sites in their sequences, although the presence of glycans is not experimentally examined in hemilipin and HgPLA2. Among the $\mathrm{N}$-glycosylation sites in these $\mathrm{PLA}_{2}$ molecules, that at the $\mathrm{N}$-terminal region of the large subunit is commonly observed. Since this site is close to the catalytic center, it may play an important role in enzymatic and/or antiviral activity.

\section{Conclusion}

Scorpion venom is known to be a rich source of bioactive peptides and proteins. Previously, we identified three insecticidal peptides from the venom of the L. australasiae scorpion, but the activities and structures of the other venom components remained unknown. In the present study, we performed a transcriptomic analysis of the venom gland of $L$. australasiae to elucidate a comprehensive picture of the venom components. As a result, 77 transcripts coding for venom peptides and proteins, including four previously reported peptides, were successfully identified. Among them, KTx-like peptides were the most diverse, suggesting that these peptides play a crucial role in this venom. On the other hand, a relatively small number of NaTx-like peptides were found. This is consistent with previous findings that $\mathrm{NaTx}$-like peptides are predominantly found in the venom of Buthidae scorpions. In addition, a relatively large number of peptides without disulfide bonds were identified, suggesting that these peptides have some critical functions in the L. australasiae venom.

These transcriptome data facilitated the structural determination of the anti-HCV component in the venom, which was obtained by a bioassay-guided approach. Mass spectrometric analysis revealed that this component is one of the $\mathrm{PLA}_{2} \mathrm{~S}\left(\mathrm{LaPLA}_{2}-1\right)$. This is the first report of a PLA 2 with antiviral activity from scorpion venom, although $\mathrm{PLA}_{2} \mathrm{~S}$ from snake and bee venom are known to show antiviral activity. Since the anti-HCV 
activity of $\mathrm{LaPLA}_{2}-1$ was inhibited by a PLA $\mathrm{PL}_{2}$ inhibitor, the enzymatic activity of $\mathrm{LaPLA}_{2}-1$ is likely to be involved in its expression of the anti-HCV activity. It is known that scvPLA 2 s, including $\mathrm{LaPLA}_{2}-1$, adopt a heterodimeric structure and are likely to be post-translationally modified by $\mathrm{N}$-glycosylation at the $\mathrm{N}$-terminal region. Elucidation of the relationship between the characteristic structures and enzymatic/antiviral activity of $\mathrm{svcPLA}_{2} \mathrm{~S}$ will be a subject of future research.

\section{Acknowledgements}

The authors are grateful to Dr. C. M. Rice (The Rockefeller University, New York, NY, U.S.A.) for providing pFL-J6/JFH1. We also thank Dr. Hajime Ono (Kyoto University) for valuable advice on the RNA extraction. This study was supported by the Cooperative Research Program of the Genome Research for BioResource, NODAI Genome Research Center, Tokyo University of Agriculture. This study was also supported in part by the Program on the Innovative Development and the Application of New Drugs for Hepatitis B from the Japan Agency for Medical Research and Development (AMED) under the grant number JP19fk0310103h2103 and by JSPS KAKENHI grant number JP19K05842.

\section{References}

Abdel-Rahman, M.A., Quintero-Hernandez, V., Possani, L.D., 2013. Venom proteomic and venomous glands transcriptomic analysis of the Egyptian scorpion Scorpio maurus palmatus (Arachnida: Scorpionidae). Toxicon 74, 193-207, 10.1016/j.toxicon.2013.08.064

Ahmadi, S., Knerr, J.M., Argemi, L., Bordon, K.C.F., Pucca, M.B., Cerni, F.A., Arantes, E.C., Caliskan, F., Laustsen, A.H., 2020. Scorpion venom: Detriments and benefits. Biomedicines 8, 118, 10.3390/biomedicines8050118

Almaaytah, A., Albalas, Q., 2014. Scorpion venom peptides with no disulfide bridges: A review. Peptides 51, 35-45, 10.1016/J.Peptides.2013.10.021 
Altschul, S.F., Gish, W., Miller, W., Myers, E.W., Lipman, D.J., 1990. Basic local alignment search tool. J. Mol. Biol. 215, 403-410, 10.1006/jmbi.1990.9999

Amorim, F.G., Longhim, H.T., Cologna, C.T., Degueldre, M., De Pauw, E., Quinton, L., Arantes, E.C., 2019. Proteome of fraction from Tityus serrulatus venom reveals new enzymes and toxins. J. Venom Anim. Toxins 25, e148218, 10.1590/1678-9199JVATITD-1482-18

Aoki-Utsubo, C., Chen, M., Hotta, H., 2018. Time-of-addition and temperature-shift assays to determine particular step(s) in the viral life cycle that is blocked by antiviral substance(s). Bio-Protocol 8, e2830, 10.21769/BioProtoc.2830

Bordon, K.C., Wiezel, G.A., Amorim, F.G., Arantes, E.C., 2015. Arthropod venom hyaluronidases: biochemical properties and potential applications in medicine and biotechnology. J. Venom Anim. Toxins Incl. Trop. Dis. 21, 43, 10.1186/s40409-015$0042-7$

Callens, N., Brugger, B., Bonnafous, P., Drobecq, H., Gerl, M.J., Krey, T., Roman-Sosa, G., Rumenapf, T., Lambert, O., Dubuisson, J., Rouille, Y., 2016. Morphology and molecular composition of purified bovine viral diarrhea virus envelope. PLOS Pathog. 12, e1005476, 10.1371/journal.ppat.1005476

Carmo, A.O., Oliveira-Mendes, B.B., Horta, C.C., Magalhaes, B.F., Dantas, A.E., Chaves, L.M., Chavez-Olortegui, C., Kalapothakis, E., 2014. Molecular and functional characterization of metalloserrulases, new metalloproteases from the Tityus serrulatus venom gland. Toxicon 90, 45-55, 10.1016/j.toxicon.2014.07.014

Chang, Z., Li, G.J., Liu, J.T., Zhang, Y., Ashby, C., Liu, D.L., Cramer, C.L., Huang, X.Z., 2015. Bridger: a new framework for de novo transcriptome assembly using RNA-seq data. Genome Biol. 16, 30, 10.1186/s13059-015-0596-2

Chen, M., Aoki-Utsubo, C., Kameoka, M., Deng, L., Terada, Y., Kamitani, W., Sato, K., Koyanagi, Y., Hijikata, M., Shindo, K., Noda, T., Kohara, M., Hotta, H., 2017. Broadspectrum antiviral agents: secreted phospholipase A2 targets viral envelope lipid bilayers derived from the endoplasmic reticulum membrane. Sci. Rep. 7, 15931, 
10.1038/s41598-017-16130-w

Chen, Z.Y., Hu, Y.T., Yang, W.S., He, Y.W., Feng, J., Wang, B., Zhao, R.M., Ding, J.P., Cao, Z.J., Li, W.X., Wu, Y.L., 2012. Hg1, novel peptide inhibitor specific for Kv1.3 channels from first scorpion Kunitz-type potassium channel toxin family. J. Biol. Chem. 287, 13813-13821, 10.1074/jbc.M112.343996

Chen, Z.Y., Wang, B., Hu, J., Yang, W.S., Cao, Z.J., Zhuo, R.X., Li, W.X., Wu, Y.L., 2013. SjAPI, the first functionally characterized Ascaris-type protease inhibitor from animal venoms. PLOS ONE 8, e57529, 10.1371/journal.pone.0057529

Cheng, Y.T., Sun, F., Li, S., Gao, M.J., Wang, L.Y., Sarhan, M., Abdel-Rahman, M.A., Li, W.X., Kwok, H.F., Wu, Y.L., Cao, Z.J., 2020. Inhibitory activity of a scorpion defensin BmKDfsin3 against hepatitis C virus. Antibiotics 9, ARTN 33, 10.3390/antibiotics 9010033

Cid-Uribe, J.I., Meneses, E.P., Batista, C.V.F., Ortiz, E., Possani, L.D., 2019. Dissecting toxicity: The venom gland transcriptome and the venom proteome of the highly venomous scorpion Centruroides limpidus (Karsch, 1879). Toxins 11, ARTN 247, $10.3390 /$ toxins 11050247

da Mata, E.C., Mourao, C.B., Rangel, M., Schwartz, E.F., 2017. Antiviral activity of animal venom peptides and related compounds. J. Venom Anim. Toxins Incl. Trop. Dis. 23, 3, 10.1186/s40409-016-0089-0

de Oliveira, U.C., Candido, D.M., Dorce, V.A.C., Junqueira-de-Azevedo, I.D.M., 2015. The transcriptome recipe for the venom cocktail of Tityus bahiensis scorpion. Toxicon 95, 52-61, 10.1016/j.toxicon.2014.12.013

Deng, L., Shoji, I., Ogawa, W., Kaneda, S., Soga, T., Jiang, D., Ide, Y.H., Hotta, H., 2011. Hepatitis $\mathrm{C}$ virus infection promotes hepatic gluconeogenesis through an NS5AMediated, FoxO1-dependent pathway. J Virol 85, 8556-8568, 10.1128/Jvi.00146-11

Deng, Y.C., Gu, J.W., Yan, Z.P., Wang, M.D., Ma, C.Q., Zhang, J.F., Jiang, G.X., Ge, M.X., Xu, S.G., Xu, Z., Xiao, L., 2018. De novo transcriptomic analysis of the venomous glands from the scorpion Heterometrus spinifer revealed unique and 
extremely high diversity of the venom peptides. Toxicon 143, 1-19, 10.1016/j.toxicon.2017.12.051

Dennis, E.A., Cao, J., Hsu, Y.H., Magrioti, V., Kokotos, G., 2011. Phospholipase A2 enzymes: physical structure, biological function, disease implication, chemical inhibition, and therapeutic intervention. Chem. Rev. 111, 6130-6185, $10.1021 / \mathrm{cr} 200085 \mathrm{w}$

Dias, N.B., de Souza, B.M., Cocchi, F.K., Chalkidis, H.M., Dorcec, V.A.C., Palma, M.S., 2018. Profiling the short, linear, non-disulfide bond-containing peptidome from the venom of the scorpion Tityus obscurus. J. Proteomics 170, 70-79, 10.1016/j.jprot.2017.09.006

Diego-Garcia, E., Peigneur, S., Clynen, E., Marien, T., Czech, L., Schoofs, L., Tytgat, J., 2012. Molecular diversity of the telson and venom components from Pandinus cavimanus (Scorpionidae Latreille 1802): Transcriptome, venomics and function. Proteomics 12, 313-328, 10.1002/pmic.201100409

El-Bitar, A.M., Sarhan, M.M., Aoki, C., Takahara, Y., Komoto, M., Deng, L., Moustafa, M.A., Hotta, H., 2015. Virocidal activity of Egyptian scorpion venoms against hepatitis C virus. Virol. J. 12, 47, 10.1186/s12985-015-0276-6

Fu, Y., Li, C., Dong, S., Wu, Y., Zhangsun, D., Luo, S., 2018. Discovery methodology of novel conotoxins from Conus species. Mar. Drugs 16, 417, 10.3390/md16110417

Gao, B., Dalziel, J., Tanzi, S., Zhu, S.Y., 2018. Meucin-49, a multifunctional scorpion venom peptide with bactericidal synergy with neurotoxins. Amino Acids 50, 1025$1043,10.1007 / \mathrm{s} 00726-018-2580-0$

Gao, R., Zhang, Y., Gopalakrishnakone, P., 2008. Purification and N-terminal sequence of a serine proteinase-like protein (BMK-CBP) from the venom of the Chinese scorpion (Buthus martensii Karsch). Toxicon 52, 348-353, 10.1016/j.toxicon.2008.06.003

Ghosh, A., Roy, R., Nandi, M., Mukhopadhyay, A., 2019. Scorpion venom-toxins that aid in drug development: A review. Int. J. Pept. Res. Ther. 25, 27-37, 10.1007/s10989- 
018-9721-x

Gordon, D., Karbat, I., Ilan, N., Cohen, L., Kahn, R., Gilles, N., Dong, K., Stuhmer, W., Tytgat, J., Gurevitz, M., 2007. The differential preference of scorpion alpha-toxins for insect or mammalian sodium channels: implications for improved insect control. Toxicon 49, 452-472, 10.1016/j.toxicon.2006.11.016

Haas, B.J., Papanicolaou, A., Yassour, M., Grabherr, M., Blood, P.D., Bowden, J., Couger, M.B., Eccles, D., Li, B., Lieber, M., MacManes, M.D., Ott, M., Orvis, J., Pochet, N., Strozzi, F., Weeks, N., Westerman, R., William, T., Dewey, C.N., Henschel, R., Leduc, R.D., Friedman, N., Regev, A., 2013. De novo transcript sequence reconstruction from RNA-seq using the Trinity platform for reference generation and analysis. Nat. Protoc. 8, 1494-1512, 10.1038/nprot.2013.084

Han, F., Lu, A., Yuan, Y., Huang, W., Beerntsen, B.T., Huang, J., Ling, E., 2017. Characterization of an entomopathogenic fungi target integument protein, Bombyx mori single domain von Willebrand factor type $\mathrm{C}$, in the silkworm, Bombyx mori. Insect Mol. Biol. 26, 308-316, 10.1111/imb.12293

Harrison, P.L., Abdel-Rahman, M.A., Miller, K., Strong, P.N., 2014. Antimicrobial peptides from scorpion venoms. Toxicon 88, 115-137, 10.1016/j.toxicon.2014.06.006 Hassani, O., Loew, D., Van Dorsselaer, A., Papandreou, M.J., Sorokine, O., Rochat, H., Sampieri, F., Mansuelle, P., 1999. Aah VI, a novel, N-glycosylated anti-insect toxin from Androctonus australis hector scorpion venom: isolation, characterisation, and glycan structure determination. FEBS Lett. 443, 175-180, 10.1016/S00145793(98)01710-4

Herzig, V., Cristofori-Armstrong, B., Israel, M.R., Nixon, S.A., Vetter, I., King, G.F., 2020. Animal toxins - Nature's evolutionary-refined toolkit for basic research and drug discovery. Biochem. Pharmacol. 181, ARTN 114096, 10.1016/j.bcp.2020.114096

Holly, M.K., Diaz, K., Smith, J.G., 2017. Defensins in viral infection and pathogenesis. Annu. Rev. Virol. 4, 369-391, 10.1146/annurev-virology-101416-041734

Horita, S., Matsushita, N., Kawachi, T., Ayabe, R., Miyashita, M., Miyakawa, T., 
Nakagawa, Y., Nagata, K., Miyagawa, H., Tanokura, M., 2011. Solution structure of a short-chain insecticidal toxin LaIT1 from the venom of scorpion Liocheles australasiae. Biochem. Biophys. Res. Commun. 411, 738-744, 10.1016/j.bbrc.2011.07.016

Housley, D.M., Housley, G.D., Liddell, M.J., Jennings, E.A., 2017. Scorpion toxin peptide action at the ion channel subunit level. Neuropharmacology 127, 46-78, 10.1016/j.neuropharm.2016.10.004

Jimenez-Vargas, J.M., Possani, L.D., Luna-Ramirez, K., 2017. Arthropod toxins acting on neuronal potassium channels. Neuropharmacology 127, 139-160, 10.1016/j.neuropharm.2017.09.025

Jridi, I., Catacchio, I., Majdoub, H., Shahbazeddah, D., El Ayeb, M., Frassanito, M.A., Ribatti, D., Vacca, A., Borchani, L., 2015. Hemilipin, a novel Hemiscorpius lepturus venom heterodimeric phospholipase A2, which inhibits angiogenesis in vitro and in vivo. Toxicon 105, 34-44, 10.1016/j.toxicon.2015.08.022

Juichi, H., Miyashita, M., Nakagawa, Y., Miyagawa, H., 2019. Isolation and characterization of the insecticidal, two-domain toxin LaIT3 from the Liocheles australasiae scorpion venom. Biosci. Biotechnol. Biochem. 83, 2183-2189, $10.1080 / 09168451.2019 .1654849$

Katoh, K., Rozewicki, J., Yamada, K.D., 2019. MAFFT online service: multiple sequence alignment, interactive sequence choice and visualization. Brief. Bioinform. 20, 1160-1166, 10.1093/bib/bbx108

Kazemi-Lomedasht, F., Khalaj, V., Bagheri, K.P., Behdani, M., Shahbazzadeh, D., 2017. The first report on transcriptome analysis of the venom gland of Iranian scorpion, Hemiscorpius lepturus. Toxicon 125, 123-130, 10.1016/j.toxicon.2016.11.261

Krayem, N., Gargouri, Y., 2020. Scorpion venom phospholipases A2: A minireview. Toxicon 184, 48-54, 10.1016/j.toxicon.2020.05.020

Kubelka, V., Altmann, F., Staudacher, E., Tretter, V., Marz, L., Hard, K., Kamerling, J.P., Vliegenthart, J.F.G., 1993. Primary structures of the N-linked carbohydrate chains 
from honeybee venom phospholipase A2. Eur. J. Biochem. 213, 1193-1204, 10.1111/j.1432-1033.1993.tb17870.x

Lassmann, T., Hayashizaki, Y., Daub, C.O., 2009. TagDust-a program to eliminate artifacts from next generation sequencing data. Bioinformatics 25, 2839-2840, 10.1093/bioinformatics/btp527

Lombardo, D., Dennis, E.A., 1985. Cobra venom phospholipase A2 inhibition by manoalide. A novel type of phospholipase inhibitor. J. Biol. Chem. 260, 7234-7240, Luna-Ramirez, K., Jimenez-Vargas, J.M., Lourival, D.P., 2016. Scorpine-like peptides. Single Cell Biol. 5, 138, 10.4172/2168-9431.1000138

Luna-Ramirez, K., Quintero-Hernandez, V., Juarez-Gonzalez, V.R., Possani, L.D., 2015. Whole transcriptome of the venom gland from Urodacus yaschenkoi scorpion. PLOS ONE 10, e0127883, 10.1371/journal.pone.0127883

Luna-Ramirez, K., Quintero-Hernandez, V., Vargas-Jaimes, L., Batista, C.V.F., Winkel, K.D., Possani, L.D., 2013. Characterization of the venom from the Australian scorpion Urodacus yaschenkoi: Molecular mass analysis of components, cDNA sequences and peptides with antimicrobial activity. Toxicon 63, 44-54, 10.1016/J.Toxicon.2012.11.017

Madeira, F., Park, Y.M., Lee, J., Buso, N., Gur, T., Madhusoodanan, N., Basutkar, P., Tivey, A.R.N., Potter, S.C., Finn, R.D., Lopez, R., 2019. The EMBL-EBI search and sequence analysis tools APIs in 2019. Nucleic Acids Res. 47, W636-W641, $10.1093 /$ nar/gkz268

Marshall, R.D., 1972. Glycoproteins. Annu. Rev. Biochem. 41, 673-702, 10.1146/annurev.bi.41.070172.003325

Matsushita, N., Miyashita, M., Ichiki, Y., Ogura, T., Sakuradani, E., Nakagawa, Y., Shimizu, S., Miyagawa, H., 2009. Purification and cDNA cloning of LaIT2, a novel insecticidal toxin from venom of the scorpion Liocheles australasiae. Biosci. Biotechnol. Biochem. 73, 2769-2772, 10.1271/bbb.90509

Matsushita, N., Miyashita, M., Sakai, A., Nakagawa, Y., Miyagawa, H., 2007. 
Purification and characterization of a novel short-chain insecticidal toxin with two disulfide bridges from the venom of the scorpion Liocheles australasiae. Toxicon 50, $861-867,10.1016 /$ j.toxicon.2007.06.014

Meng, L.X., Xie, Z.L., Zhang, Q., Li, Y., Yang, F., Chen, Z.Y., Li, W.X., Cao, Z.J., Wu, Y.L., 2016. Scorpion potassium channel-blocking defensin highlights a functional link with neurotoxin. J. Biol. Chem. 291, 7097-7106, 10.1074/jbc.M115.680611

Mishra, M., 2020. Evolutionary aspects of the structural convergence and functional diversification of Kunitz-domain inhibitors. J. Mol. Evol., 537-548, 10.1007/s00239020-09959-9

Miyashita, M., Kitanaka, A., Yakio, M., Yamazaki, Y., Nakagawa, Y., Miyagawa, H., 2017. Complete de novo sequencing of antimicrobial peptides in the venom of the scorpion Isometrus maculatus. Toxicon 139, 1-12, 10.1016/j.toxicon.2017.09.010

Miyashita, M., Otsuki, J., Hanai, Y., Nakagawa, Y., Miyagawa, H., 2007.

Characterization of peptide components in the venom of the scorpion Liocheles australasiae (Hemiscorpiidae). Toxicon 50, 428-437, 10.1016/j.toxicon.2007.04.012

Miyashita, M., Sakai, A., Matsushita, N., Hanai, Y., Nakagawa, Y., Miyagawa, H., 2010. A novel amphipathic linear peptide with both insect toxicity and antimicrobial activity from the venom of the scorpion Isometrus maculatus. Biosci. Biotechnol. Biochem. 74, 364-369, 10.1271/bbb.90723

Oldrati, V., Arrell, M., Violette, A., Perret, F., Sprungli, X., Wolfender, J.L., Stocklin, R., 2016. Advances in venomics. Mol. Biosyst. 12, 3530-3543, 10.1039/c6mb00516k

Plummer, T.H., Tarentino, A.L., 1981. Facile cleavage of complex oligosaccharides from glycopeptides by almond emulsin peptide - N-glycosidase. J. Biol. Chem. 256, 243-246,

Quintero-Hernandez, V., Jimenez-Vargas, J.M., Gurrola, G.B., Valdivia, H.H., Possani, L.D., 2013. Scorpion venom components that affect ion-channels function. Toxicon 76, 328-342, 10.1016/J.Toxicon.2013.07.012

Quintero-Hernandez, V., Ortiz, E., Rendon-Anaya, M., Schwartz, E.F., Becerril, B., 
Corzo, G., Possani, L.D., 2011. Scorpion and spider venom peptides: gene cloning and peptide expression. Toxicon 58, 644-663, 10.1016/j.toxicon.2011.09.015

Quintero-Hernandez, V., Ramirez-Carreto, S., Romero-Gutierrez, M.T., ValdezVelazquez, L.L., Becerril, B., Possani, L.D., Ortiz, E., 2015. Transcriptome analysis of scorpion species belonging to the Vaejovis genus. PLOS One 10, e0117188, 10.1371/journal.pone. 0117188

Ranasinghe, S., McManus, D.P., 2013. Structure and function of invertebrate Kunitz serine protease inhibitors. Dev. Comp. Immunol. 39, 219-227, 10.1016/j.dci.2012.10.005

Romero-Gutierrez, M.T., Santibanez-Lopez, C.E., Jimenez-Vargas, J.M., Batista, C.V.F., Ortiz, E., Possani, L.D., 2018. Transcriptomic and proteomic analyses reveal the diversity of venom components from the vaejovid scorpion Serradigitus gertschi. Toxins 10, 359, 10.3390/toxins 10090359

Santibanez-Lopez, C.E., Cid-Uribe, J.I., Batista, C.V., Ortiz, E., Possani, L.D., 2016. Venom gland transcriptomic and proteomic analyses of the enigmatic scorpion Superstitionia donensis (Scorpiones: Superstitioniidae), with insights on the evolution of its venom components. Toxins 8, 367, 10.3390/toxins8120367

Schwartz, E.F., Diego-Garcia, E., Rodriguez de la Vega, R.C., Possani, L.D., 2007. Transcriptome analysis of the venom gland of the Mexican scorpion Hadrurus gertschi (Arachnida: Scorpiones). BMC Genomics 8, 119, 10.1186/1471-2164-8-119

Schwartz, E.F., Mourao, C.B., Moreira, K.G., Camargos, T.S., Mortari, M.R., 2012. Arthropod venoms: a vast arsenal of insecticidal neuropeptides. Biopolymers 98, 385405, 10.1002/bip.22100

Sheldon, T.J., Miguel-Aliaga, I., Gould, A.P., Taylor, W.R., Conklin, D., 2007. A novel family of single VWC-domain proteins in invertebrates. FEBS Lett 581, 5268-5274, 10.1016/J.Febslet.2007.10.016

Silva, E.C.N., Camargos, T.S., Maranhao, A.Q., Silva-Pereira, I., Silva, L.P., Possani, L.D., Schwartz, E.F., 2009. Cloning and characterization of cDNA sequences encoding 
for new venom peptides of the Brazilian scorpion Opisthacanthus cayaporum. Toxicon 54, 252-261, 10.1016/J.Toxicon.2009.04.010

Smith, J.J., Alewood, P.F., 2015. Modern venom profiling: Mining into scorpion venom biodiversity, in: Gopalakrishnakone, P., Possani, L.D., Schwartz, E.F., Rodríguez de la Vega, R.C., (Eds), Scorpion Venoms. Springer, Dordrecht.

Smith, J.J., Herzig, V., King, G.F., Alewood, P.F., 2013. The insecticidal potential of venom peptides. Cell. Mol. Life Sci. 70, 3665-3693, 10.1007/s00018-013-1315-3

Smith, J.J., Hill, J.M., Little, M.J., Nicholson, G.M., King, G.F., Alewood, P.F., 2011. Unique scorpion toxin with a putative ancestral fold provides insight into evolution of the inhibitor cystine knot motif. P. Natl. Acad. Sci. USA 108, 10478-10483, 10.1073/pnas. 1103501108

Song, J., Fujii, M., Wang, F., Itoh, M., Hotta, H., 1999. The NS5A protein of hepatitis C virus partially inhibits the antiviral activity of interferon. J Gen Virol 80, 879-886, $10.1099 / 0022-1317-80-4-879$

Soudani, N., Gharbi-Chihi, J., Srairi-Abid, N., Martin-El Yazidi, C., Planells, R., Margotat, A., Torresani, J., El Ayeb, M., 2005. Isolation and molecular characterization of LVP1 lipolysis activating peptide from scorpion Buthus occitanus tunetanus. BBA-Proteins Proteom. 1747, 47-56, 10.1016/j.bbapap.2004.09.020

Staudacher, E., Altmann, F., Marz, L., Hard, K., Kamerling, J.P., Vliegenthart, J.F.G., 1992. Alpha-1-6(alpha-1-3)-difucosylation of the asparagine-bound Nacetylglucosamine in honeybee venom phospholipase-A2. Glycoconjugate J. 9, 82-85, 10.1007/Bf00731703

Teixeira, S.C., Borges, B.C., Oliveira, V.Q., Carregosa, L.S., Bastos, L.A., Santos, I.A., Jardim, A.C.G., Melo, F.F., Freitas, L.M., Rodrigues, V.M., Lopes, D.S., 2020. Insights into the antiviral activity of phospholipases A2 (PLA2s) from snake venoms. Int. J. Biol. Macromol. 164, 616-625, 10.1016/j.ijbiomac.2020.07.178

Valdez-Cruz, N.A., Batista, C.V.F., Possani, L.D., 2004. Phaiodactylipin, a glycosylated heterodimeric phospholipase A2 from the venom of the scorpion Anuroctonus 
phaiodactylus. Eur. J. Biochem. 271, 1453-1464, 10.1111/j.1432-1033.2004.04047.x

Vetter, I., Davis, J.L., Rash, L.D., Anangi, R., Mobli, M., Alewood, P.F., Lewis, R.J., King, G.F., 2011. Venomics: a new paradigm for natural products-based drug discovery. Amino Acids 40, 15-28, 10.1007/s00726-010-0516-4

Walker, A.A., Robinson, S.D., Hamilton, B.F., Undheim, E.A.B., King, G.F., 2020. Deadly proteomes: A practical guide to proteotranscriptomics of animal venoms. Proteomics 20, ARTN 1900324, 10.1002/pmic.201900324

Walski, T., De Schutter, K., Van Damme, E.J.M., Smagghe, G., 2017. Diversity and functions of protein glycosylation in insects. Insect Biochem. Mol. Biol. 83, 21-34, 10.1016/j.ibmb.2017.02.005

Wang, H.D., Smagghe, G., Meeus, I., 2017. The role of a single gene encoding the single von Willebrand factor C-domain protein (SVC) in bumblebee immunity extends beyond antiviral defense. Insect. Biochem. Mol. Biol. 91, 10-20, 10.1016/j.ibmb.2017.10.002

Ward, M.J., Ellsworth, S.A., Rokyta, D.R., 2018. Venom-gland transcriptomics and venom proteomics of the Hentz striped scorpion (Centruroides hentzi; Buthidae) reveal high toxin diversity in a harmless member of a lethal family. Toxicon 142, $14-$ 29, 10.1016/j.toxicon.2017.12.042

Wullschleger, B., Nentwig, W., Kuhn-Nentwig, L., 2005. Spider venom: enhancement of venom efficacy mediated by different synergistic strategies in Cupiennius salei. $\mathrm{J}$ Exp Biol 208, 2115-2121, 10.1242/jeb.01594

Yacoub, T., Rima, M., Karam, M., Fajloun, J., 2020. Antimicrobials from venomous animals: An overview. Molecules 25, 2402, 10.3390/molecules25102402

Yang, Y., Zeng, X.C., Zhang, L., Nie, Y., Shi, W.X., Liu, Y.C., 2014. Androcin, a novel type of cysteine-rich venom peptide from Androctonus bicolor, Induces akinesia and anxiety-like symptoms in nice. IUBMB Life 66, 277-285, 10.1002/iub.1261

Yi, H.Y., Chowdhury, M., Huang, Y.D., Yu, X.Q., 2014. Insect antimicrobial peptides and their applications. Appl. Microbiol. Biot. 98, 5807-5822, 10.1007/s00253-014- 
$5792-6$

Zeng, X.C., Nie, Y., Luo, X.S., Wu, S.F., Shi, W.X., Zhang, L., Liu, Y.C., Cao, H.J., Yang, Y., Zhou, J.P., 2013. Molecular and bioinformatical characterization of a novel superfamily of cysteine-rich peptides from arthropods. Peptides 41, 45-58, 10.1016/j.peptides.2012.10.004

Zhang, L., Shi, W.X., Zeng, X.C., Ge, F., Yang, M.K., Nie, Y., Bao, A., Wu, S.F., E, G.J., 2015. Unique diversity of the venom peptides from the scorpion Androctonus bicolor revealed by transcriptomic and proteomic analysis. J. Proteomics 128, 231250, 10.1016/j.jprot.2015.07.030

Zhao, R.M., Ma, Y.B., He, Y.W., Di, Z.Y., Wu, Y.L., Cao, Z.J., Li, W.X., 2010.

Comparative venom gland transcriptome analysis of the scorpion Lychas mucronatus reveals intraspecific toxic gene diversity and new venomous components. BMC Genomics 11, 452, 10.1186/1471-2164-11-452

Zhao, Y., Chen, Z., Cao, Z., Li, W., Wu, Y., 2019. Diverse structural features of potassium channels characterized by scorpion toxins as molecular probes. Molecules 24, 2045, 10.3390/molecules 24112045

Zhong, J., Zeng, X.C., Zeng, X., Nie, Y., Zhang, L., Wu, S., Bao, A., 2017.

Transcriptomic analysis of the venom glands from the scorpion Hadogenes troglodytes revealed unique and extremely high diversity of the venom peptides. J. Proteomics 150, 40-62, 10.1016/j.jprot.2016.08.004

Zhu, S., Gao, B., 2006. Molecular characterization of a new scorpion venom lipolysis activating peptide: Evidence for disulfide bridge-mediated functional switch of peptides. FEBS Lett. 580, 6825-6836, 10.1016/j.febslet.2006.11.040

Zhu, S.Y., Peigneur, S., Gao, B., Umetsu, Y., Ohki, S., Tytgat, J., 2014. Experimental conversion of a defensin into a neurotoxin: Implications for origin of toxic function. Mol. Biol. Evol. 31, 546-559, 10.1093/molbev/msu038 
Table 1 List of the peptide fragments generated by enzymatic digestions

\begin{tabular}{lrrr}
\hline \multirow{2}{*}{ Peptide sequence } & \multicolumn{2}{c}{ Molecular mass (Da) } & \multirow{2}{*}{$\begin{array}{c}\text { Mass } \\
\text { difference }\end{array}$} \\
\cline { 2 - 3 } Lys-C digestion & \multicolumn{1}{c}{ Obs. } & Calc. & \\
LIFPGTK & 774.46 & 774.47 & -0.01 \\
WCGAGDK & 793.30 & 793.31 & -0.01 \\
AANYSDLGSAAETDK & 2209.90 & 1511.68 & 698.22 \\
CCRAHDHCDNIAAGETK & 2016.74 & 2016.78 & -0.04 \\
YGLENSYWFTK & 1406.63 & 1406.66 & -0.03 \\
CEESFRNCLAEAK & 1614.64 & 1614.67 & -0.03 \\
FSYFNVYGPK & 1220.57 & 1220.59 & -0.02 \\
CFVLDCD & 929.30 & 929.32 & -0.02 \\
Lys-C digestion after PNGase A treatment & & & \\
AADYSDLGSAAETDK & 1512.69 & 1512.67 & 0.02 \\
Glu-C digestion & & & \\
LIFPGTKWCGAGDKAANYSDLGSAAE & 3397.39 & 2699.25 & 698.14 \\
TDKCCRAHDHCDNIAAGETKYGLE & 2823.04 & 2823.16 & -0.12 \\
NSYWFTKLNCKCEE & 1879.70 & 1879.78 & -0.08 \\
SFRNCLAE & 996.40 & 996.44 & -0.04 \\
TTAKFVKFSYFNVYGPKCFVLDCD & 2907.22 & 2907.36 & -0.14 \\
\hline
\end{tabular}


Table 2 Virucidal activity of $\mathrm{LaPLA}_{2}-1$

\begin{tabular}{lc}
\hline Virus & $\mathrm{IC}_{50}(\mathrm{ng} / \mathrm{ml})^{\mathrm{a}}$ \\
\hline HCV & $2.0 \pm 0.3$ \\
HCV (+ manoalide $)$ & $>500$ \\
DENV & $3.4 \pm 0.6$ \\
JEV & $5.7 \pm 0.8$ \\
HSV-1 & $>1,000$ \\
\hline
\end{tabular}

${ }^{a}$ The data represent means \pm SEM from three independent experiments. 
Table S1 Sequences of peptides identified by the transcriptome analysis of the venom gland.

\begin{tabular}{|c|c|c|}
\hline Name & Sequence & Similar peptide (Accession number, species) \\
\hline \multicolumn{3}{|c|}{ Non-disulfide-bridged peptide } \\
\hline LaNDBP2-1 & MNIKVVLVVCLITLLVTEQVEGGWFSRIKSLAKKAWKSNLAKDLRKMAGKAARNYAAKVLNVSPEEQVQLDNLLRYLD & Vejovine (F1AWB0, Vaejovis mexicanus) \\
\hline LaNDBP2-2 & MNGKVLVVCLIVAMLVMEPAEAGIWGWIKKTAKKVWNSDIANQLKNKALNAAKNYVAEKVGATPAEAGQMPFDEFMDIYYS & Con22 (L0GBQ6, Urodacus yaschenkoi) \\
\hline LaNDBP3-1 & MQYKTFLVIFLAYLLVTEEAQAFWWALAKGAAKLLPSVVGAFTKRKREIEKIFDPYQSSLDLEMERFLRQLQ & Heterin 2 (AGK88595, Heterometrus spinifer) \\
\hline LaNDBP3-2 & MKLRTLMVIFLAYLIVTDEAEAFWGFLAKAAAKLLPSLFSSKKEKEKREIEHFFDPYEKELDSELDQLLYELQ & Heterin 2 (AGK88595, Heterometrus spinifer) \\
\hline LaNDBP4-1 & MKIQLAILVITVVLMQMLVQTEAGFWGKLWEGVKNVIGKRGLRNKDQLDDLFDSDLSDADAKLLREMFK & OcyC2 (C5J887, Opisthacanthus cayaporum) \\
\hline LaNDBP4-2 & MKIQLAILVITVVLMQMLVQTEASFWGKLWEGVKSAIGKRGLRDVDQMDDLFDSDLSDADAKLLREIFK & OcyC2 (C5J887, Opisthacanthus cayaporum) \\
\hline LaNDBP4-3 & MKNQFVILLLAIVFLQLFSQSEAFLSALWGVAKSLFGKRGLKNLDQLDDLFDGEVSEADLDFLKELMR & UyCT3 (LOGCI6, Urodacus yaschenkoi) \\
\hline LaNDBP4-4 & MKAQIVLLVITVVLMQMFAQSEAGFWGKLWEGVKSAIGKRGLRNLDQFDDELFDSDLSDADAKLLKEIFK & UyCT1 (LOGCV8, Urodacus yaschenkoi) \\
\hline LaNDBP4-5 & MRLVSLTPLFLILLIAVDYCQSFPFLLSLIPSAISALKKLGKRSTDFQRQLDFQRRYLNSDLDFDLDELEEFLDQLPDY & VpAmp1.0 (ALG64974, Vaejovis punctatus) \\
\hline \multicolumn{3}{|c|}{ Invertebrate defensin } \\
\hline LaDefensin1 & MKAIATLLLILVAFSVLEFGIVDAGFGCPFNRYQCHSHCQSIKRRGGFCAGTFRTTCTCYKSK & AbDef-1 (AIX87626, Androctonus bicolor) \\
\hline LaDefensin2 & MKAIATLLLLLVAFSILEDGIVDAGFGCPFNRYQCHSHCRSIGRRGGYCSGPFRFTCTCYK & AbDef-1 (AIX87626, Androctonus bicolor) \\
\hline LaDefensin3 & MKAIATILLLLAAFSILEFGIVGAGFGCPHNRYQCHSHCQSIGRNGGYCGGTFRTTCTCYNSGGPTSSP & AbDef-1 (AIX87626, Androctonus bicolor) \\
\hline \multicolumn{3}{|c|}{ Potassium channel toxin-like peptide (alpha) } \\
\hline La-alphaKTx1 & MNAKFIYILLLTAVMFALYEASVPPNIPCQVTNQCPKPCREATGRPNSKCINGRCKCYG & Urotoxin (PODL37, Urodacus yaschenkoi) \\
\hline La-alphaKTx2 & MNTKFVFLLLVISTLMPTFDASAEDISCSSSKECYDPCEEETGCSSAKCVGGWCKCYGCRG & Urotoxin (PODL37, Urodacus yaschenkoi) \\
\hline La-alphaKTx3 & MNRNFVFLLLLIVTLMPMLDAATEDINCDNWRDCLKPCKDETGCPNSKCEEGNCLCYGCNRLTV & Urotoxin (PODL37, Urodacus yaschenkoi) \\
\hline La-alphaKTx4 & MNKKFIFLLLVVTTLMPMFDAATEAISCSNPNDCREPCKKQTGCSGGKCMNRKCKCHRCNG & OcKTx2 (Q6XLL8Opistophthalmus carinatus) \\
\hline La-alphaKTx5 & MNAKLVCIVLLTAVMFAPDEASLPPIRIPCYVSKDCRKPCLYLTGTPRSKCINRRCKCYG & Hemitoxin (P85528, Hemiscorpius lepturus) \\
\hline La-alphaKTx6 & MNKPFCAIFLVVLIMFAVSVLPAESTGGCPVDSLCKSYCKSNKFGTEGKCDGTSCKCAIG & LmKTx8 (A9QLM3, Lychas mucronatus) \\
\hline La-alphaKTx7 & MNKLACYILICVMVSCLFKVPVAEGISAGCPLTAKLCTIYCKKHRFGREGKCIGPTRFRCKCYV & LmKTx8 (A9QLM3, Lychas mucronatus) \\
\hline
\end{tabular}


$\begin{array}{ll}\text { La-alphaKTx8 } & \text { MRLVIILLLMTTLVLAVGAPLGGAKCSSSTQCTRPCRYAGGTHGKCMNGRCRCYG } \\ \text { La-alphaKTx9 } & \text { MELKYLLVLLAVTCLVSCQDNSLLPSGSCSRTGICMESCAPFLYQPKYHRRCPAGYVCCTLIY }\end{array}$

St20 (P0DP36, Scorpiops tibetanus)

Potassium channel toxin-like peptide (beta)

\begin{tabular}{|c|c|c|}
\hline $\begin{array}{l}\text { La-betaKTx1 } \\
\text { (LalT2) }\end{array}$ & MAKHLIVMFLVIMVISSLVDCAKKPFVQRVKNAASKAYNKLKGLAMQSQYGCPIISNMCEDHCRRKKMEGQCDLLDCVCS & Previously identified \\
\hline $\begin{array}{l}\text { La-betaKTx2 } \\
\text { (LalT3) }\end{array}$ & $\begin{array}{l}\text { MQAQFTVLLLLVLVTLCSCGGILREKYFHKAADALTSNIPIPVVKDVLKSAANQMIRKIGKVQQACAFNKDLAGWCEKSCQEAE } \\
\text { GKKGYCHGTKCKCGKPIDYRK }\end{array}$ & Previously identified \\
\hline La-betaKTx3 & $\begin{array}{l}\text { MDTKLSILVFLCVVVIASCSWISEKRIQKALDEKLPKGFIQGAAKAIVHKFAKNQYGCLADMDVKGSCDRHCQETESTNGVCHG } \\
\text { TKCKCGIGRVY }\end{array}$ & SCl1 (L0G8Z0, Urodacus yaschenkoi) \\
\hline
\end{tabular}

\section{Potassium channel toxin-like peptide (delta)}

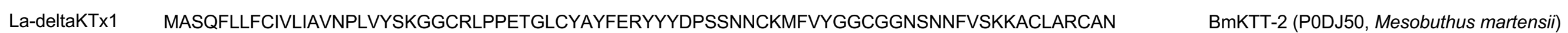

\section{Potassium channel toxin-like peptide (kappa)}

La-kappaKTx1 MKPSTSAYALLLVLTFGIITSGVFAVPMDEENTFEVEKRGNSCMEVCLQHEGNVAECEKACNKG

La-kappaKTx2 MKPSTSAFILLLVLTFGIITSGVSAIPMDEENTFEEQKRDSACVEVCLHHEGNVAECEEACKKS

La-kappaKTx3 MKLLPLLVILIICALMANEAFCDQGARERSENLEDTRDLVQKPCRIVCSENMRKCIRRCTLGR

La-kappaKTx4 MKPSSFAIALILVLFLGFTNAVSGEYAESISGDRMERAERAGCRIRCLQFTDDFEKCRKLCG

La-kappaKTx5 MKLLPLLLVILIVCALLPNEAFCDQSAVERSESLEEVSREIVKRSCKRVCSGTRRTKKCMQKCKSQPGR

\section{DDH peptide}

\section{LaDDH1}

(LalT1)

$\mathrm{LaDDH} 2$
MNFATKVFFLLLAVAVIAIVAGEEDDSWFEQNEESDTERDFPLSKEYETCVRPRKCQPPLKCNKAQICVDPKKGW

MNCAIKVSFLLLAITVIFSVAGGEGDNSFEQREENDTERDLPLSKKHESCVRPRKCRPPLRCNKAHICVESKKGWRIPVISWVS KTKIMFSE

\section{Sodium channel toxin-like peptide}

LaLAP1 MNTGEHFASLIIFLLLLGENPCLGDGGWPMRIDGNYYLCYYEEKPAELYCKRACKLHKASQSSCSYHWKYMSWYCYCEDLKK GYTRDRGLKKGGGHQFSES

LaLAP2 MLMVIYIATLIPLILQGECRAKDDHPRNFEGNCYRCKYPDKSGYCEAICKMHKAETGYCSRSNLFCYCKGIEDKYVSARDFLEP

\section{La1-like peptide}

$\begin{array}{ll}\text { La1 } & \text { MGGTLKHLLLVLIVVCSSSLCLGFGESCIAGRFIVPLGQQVTDQRDCALYKCVNYNKKFALETKRCATVNLKSGCKTVPGGA } \\ \text { La1-1 } & \text { MKHLHAAVLLVCLSICALPSLTLGAGESCKVGSLVIPVGQKKFDKPSCAEYECSTEFNRVLLKAITCATLNTKGKGCKSVPGKS } \\ & \text { PNSFPDCCPTILCRGEQWNH }\end{array}$

Previously identified

La1-like protein 15 (LOGB04, Urodacus yaschenkoi)

HeTx203 (P0DJ34, Heterometrus petersii)

HelaTx1 (P0DJ41, Heterometrus laoticus)

PcavC10 (AEX09227, Pandinus cavimanus)

HelaTx1 (P0DJ41, Heterometrus laoticus)

LalT1 (P0C5F2, Liocheles australasiae)

yaschenkoi)


La1-2 MKIVCTLVPLVFACIANAHVLTERTCRTHTGVILKNGEEWADPNHCSIYRCTIYSGEAELQGLTCATYRVPPNCEFVRGRGKFY PSCCPTVMCKP

MALRFVLAFLLPCLVLGSNEPAKFISYKNDMLGPLVEGKCKVGNDKMIEQGGTWYRDDYCEKIYCLRTGTLGHMEVWGCAPV APLNPNCTVVHHSGLYPNCCSGEIVCEENPDTKKSDVEMAEIIRALLQSERK

MFNIVTITLLWSCTCIALCHSYGETCQAGELTIPLDNEKQDPEACTLYKCTMFAGRVVLNTLTCAPQEPRRGCRNVDSPVELPF PDCCPLVVCNVQPLGSK

MRTLVPAVFLLALIVAAMASHKDPYHRNCPIGNKDLSDGEEWADQQRCVKYKCQIRGPDAALLLTRCPSVGIYPPDKCREIAG KGNFPDCCPKLQCD

MSRADKAFVGTLIAIFLVCSLTNAYSSLKRQKYGSGAPCVDHLGSNRKFDDVWYDNESCEEHTCIKYRGIPHVQIYGCIAAVAS PGCELVKGSGSYPDCCEEEIC

MKTWEARFYIFLVALVTITFVESYVYLVPQDPGAVVCIGKDRVSHKPGDVWYDDSKCERLTCGHSSGGLVIDGAGCGSISVQD GCKLVPGVGSYPSCCPSPVC

La1-7
OcyC11 (C5J895, Opisthacanthus cayaporum)

MeVP-7 (ABR21061, Mesobuthus eupeus)

HsVx1 (K7WMX6, Heterometrus spinifer)

MmKTx1-like (XP_02321219, Centruroides sculpturatus)

TXLP9 (ABY26691, Lychas mucronatus)

Toxin-like protein 14 (LOGCW8, Urodacus yaschenkoi)

\section{Serine protease inhibitor-like peptide}

LaAPI1 MKSWTYRLCFLILFLVCVNCTRPVLSPEECTRPGEFFTTAGSYCPLTCDNYKNPPIICSLIGIVGCECSPELVRDERSGNCVDTS DCTED

LaAPI2

MKGFAFLVLTFVVVFGDKEQECEDPNAEFRRCNTACPITCANMDNPPNICTLQCVIGCACKEGYYKNDDGLCVHPEGC

LaAPI3

MKALLLLLSFVVIHSAKSQEDLGGDEHAQSCLLPNEVWDKCGPSCPPSCIGVIEPGTLCSTECTPGCFCREGLVRTKRGSCIPP KACRNERETKL

MKGSKPLCFLYLVVLLWTSVKCTRWASSSEECTRPGEAFTSCGTDCPITCANYENPPEFCNYMCVIGCECTSGLVRDEGSGN CVNPSQCGP

LaAPI4

MKRNLVLLAFVLLLFGSIFEKCSAQRGGADRRCRRPGEVFMNCGPSCPLTCDNYQNPPTVCTLQCVIGCFCRRGLVRDTRRG GCVRPSQCRR

LaAPI5 MKRNLALSALFVLLFCSALDNCEAQRGGYDRTCQLEGEVFTRCGTACPLTCDNYKNPPEVCTLQCIIGCVCGRGWVKDTRRG RCVRPSQCRR

LaAPI6 MKSNLVLFAFVLLLFCSVLEICTAQRRVVDRSCRGAGEVFTRCGTACPLTCDNYRNPPRFCTRQCIIGCACRRGWVKATRRG

LaAPI7 GCVRPSQCRR

LaAPI8
SjAPI (P0DM55, Scorpiops jendeki)

SjAPI (P0DM55, Scorpiops jendeki)

SjAPI-2 (P0DM56, Scorpiops jendeki)

HtPi1 (AOF40217, Hadogenes troglodytes)

HtPi1 (AOF40217, Hadogenes troglodytes)

HtPi2 (AOF40218, Hadogenes troglodytes)

HtPi2 (AOF40218, Hadogenes troglodytes)

CtAPI (P0DM57, Chaerilus tricostatus) 
Table S2 Sequences of proteins identified by the transcriptome analysis of the venom gland

Name

Sequence

\section{Phospholipase $A_{2}$}

$\operatorname{LaPLA}_{2}-1$

MVFIFLAVLSGLVTLSHSTAVQREMHVHFEPLPGQRDSWPVARAALVNLATKSETGREFSDCRMLNSIDEIAREGAVLSRYEIK RVSKEEMRSLEKRCSRSSGIHQRLIFPGTKWCGAGDKAANYSDLGSAAETDKCCRAHDHCDNIAAGETKYGLENSYWFTKLN CKCEESFRNCLAEAKKKETTAKFVKFSYFNVYGPKCFVLDCDKRRFEMSRKCVAHWKESRRG

$\mathrm{LaPLA}_{2}-2$

MMVSSLLIVLIVTSAVQCYVIDNMNDEEPLVTFYREKDGRRTVEVIEVNDNKKGPKIVGCVEYGDGYIADMVLNLSRNILVRDVN RQQMDEVVNRCRERETRDLRNEVINLFKSPAETSRNAFQSLMIFPGTKWCGAGNVSENYDDLGTARATDMCCRDHDHCND SIERFGSKHGLENTDFYTKSNCDCDNKLYSCLEASKDVTSDLVGYLYFNIMQTQCFKKYYPEVKCLKKTGILFFMQSCQEYEF NRNEPKKYEFFDAKYYEPQAASLEQIMSYFYSSSSQ

$\mathrm{LaPLA}_{2}-3$

MSLQTLAVLLLSFIQPLPTAVIELPHENKLTGYYQNERSPYMLIIGQTGKVIHCHQYEDKNEADRVLAALKLEDVERVTKEQMDK LIKFCTEEEHMGHPKEQVKMLIYPGTKWCGMGNNAASENELGTEKEADSCCREHDHCSDSIPAFSIKYNLTNYSPFTKSNCNC DREFRQCLTKAGTKASEIISGLYFDLLKMECFGRTSCSSNDACTEGWQWKRSTSF

\section{Serine protease}

LaSP1

MKYASLIASVFLLTQTEACTETGEHNQIRFPEEEEESCRTPNGRRGVCVPLNACPEFRNADDRYIRQSICWFDRNTPVVCCPS NEQPVTMPTHPTRPTRPTRPTRPTQPPTCPPVSPVTRCPVVGPNRRKPSILPEECGKSTVPLSRIVGGRKSDLGAWPWMVAV YLTRAGLNRGTDCGGSLISDKHVLTAAHCVYDKRRKTVMSASQLMVRVGEHTLNDDNDGASPIDVPVSNIMAHENFERKTFK NDIAILVLANTVQFSQFIRPICLPYDESSEANFTGRSAFVAGWGETEYEGQFNPELSEIQIPILNNEVCRQKYKRNIPITAEYLCA GVSDGTKDSCRGDSGGPLMLPEKDNRFYLIGVVSFGKRCATYGYPGVYTRMTMYLDWLASKLS

LaSP2

MWARFGLTFLFCYYLQNTFIGAEAQACGTRNMTLEFKIVGGTVAARGEWPWQVSVQLTHPQFGKIGHWCGGVLVGQQWVA TAAHCIINPLFSLPQPVFWKVLLGDHHIKKTEGSEVVIGVSRVYYNPWYHGYQNDIALLKLSEPVKLSSYIQPICLPTSNDGFQD MTCTATGWGKTDFNMKASDTLQKVDVKVLDNSICANAYLTQFKIPITPSHLCAGDTAGGKGTCLGDSGGPLQCLMPNGKWYL AGLTSFGSGCAKPGFPDVYTRVTYYVDWIKQNQLLPW

LaSP3

MNLIGLVALACVTLSSRVEARFLHDPSEESGRVFRGRFANQQEFPWMVHLQISKGNNMASVCGGSVISKNWVLTAAHCVCRN ATLKTYADVNGITGRIGHVNKSSATAVKFSQLIVHNSYDEDFNADIALLKFKDSLKKYDANVNRICLADKGKTFPNRQPVIQMG WGRFDNSSAGTSPSLKTTSVGYILHRADCIKEQESYADPGQICVSNFKGEKICGGDSGGPLVVANGAEKLDIGIVSYDYYSFCV AGSDSPAMYTEISYYADWIKTKTNDKEICWKK
MLWSTRDSAIFLLFIITLNSRFNYSSNQGFFLNRRSDGNTCTRNGEVHQCQFFLFCLLGGGTSMGSCSGRVLTTCCAKPNLRR SRPSNFRQRALNNKDRASCGQTAWKPQSRIVGGQDALYGEFPWQAHIKIIQQQCGGVIVSPYFVVTAAHCVYRARLHQITVVL GAYDIHDQSFQLQPALFLRVDEKRLHPNFKFSPSHPDRYDVALLRLHRRVQYQENILPICLPPYKWNFRGWRAVVIGWGKTDP ALRNRYGTRLLQKVEVPIISNDECEYWHKSRGIKLKIYPEMICAGYEHGKKDACVGDSGGPLMVNMRGKWTLVGITSAGFGCA QWRQPGIYHSVSSTVDWINANIR
Similar protein (Accession number, species)

Hemilipin (A0A1L4BJ46, Hemiscorpius lepturus)

Phaiodactylipin (Q6PXP0, Anuroctonus phaiodactylus)

Hemilipin (A0A1L4BJ46, Hemiscorpius lepturus) Serine protease 1 (AMO02563, Tityus serrulatus)

Chymotrypsin-like protease-3 (ABR21040,

Mesobuthus eupeus)

Serine protease 3 (AMO02565, Tityus serrulatus) 
LaSP5

MAISLLVKYAILWISLAVLSSAQSALPDRRPNSFVFPETVRDSPRCRTADGSPGSCLKASECRDVNFQRGTLPLLCYWEDNQPI VCCADRSAAISSENLSEPQTGCGKSERKPTTRSPTIAGGWISQPSAWPWMVAILTSNLGEKFLCGGTLVSQKYVLTAAHCFRR NGVDQRRIPVARFLVRVGSTENNQGTAYRIRRIMIHEDYRVNQHYNDIAVIEVNDPISLSSSVRPICLPSSELQGRSVVGREVVV VGWGDQSFGGIRDNKLREVNISVIDRDTCNEAYNELSSRSIPNGITSQFMCAGDPEGGKDACQADSGGPLMMFSPSQWSIVG VVSFGYGCAHKGFPGVYTQVSSYLNWIKDKTDL

LaSP6

MAMKYFVLFISTNALLAASFLPAKEENRIFKGREANEGEFPWMVFIRLTDELNCSGFLVSHNYVVTAAHCMIRSVTDMKGVVGS VDREQDNMLEFEKFVIHPEYNESTFHGDVALLKLKRPLEFTSLIKPICIGKKKSFINPGNEVLQMGWGRDRNDSAVVSKILKVTN VGSVMSEEHCHTFLGMINFTSIGRICVKNGEVEGVCEGDSGGPLVYKDSEHGNVAVGLSSFGFYLNCSVTNENPEIFTSTAYF SNWIAENVEDSVCVIG

LaSP7

MFKSFELIYLAIACIGSGSVIFAKNCDDCILITSCPGAVYLAVHAKNAKTEDLIKHSLCSLEKVNGLPKVCCSEFPPAPQLDNHPN LELLPKDCGEIEGSRIVGGEVAKLYEFPWMVLISYDTRIGREFLCGGSLISPLYVLTAAHCVHGRKIAGVRIGDYDWRSKIDCEK DTNLCESYYQDIGVSERLPHPDYQGPPVVRNDIALLRLRRPVNLTVKNAGVICLPVTKELRERRLDTEQVTVAGWGITENNTAS SVLLKVNLPVHSGEMCRAYYGRNSKEDTTKNILCAGVLGKDSCKGDSGGPLMLEGNYDNVFKFIQYGIVSYGPSQCGSNFPG VYTDVSSFMKWILDNIKP

LaSP8

MKCFAFLIFSSQLFPAVPFQVEEKTRIFGGREANDGEFPWMVFIRLSAEWNCGGFLISPSYVLTAAHCVKGSSVTDMRGVVGS VDREQQDMLEFKKYQIHPEYGPKRRWNADLALLELRTPLGFTDLIKPICIGKKTSFTRPGNAVLQMGWGRDREDSAVVTKKLK VTEVGNLMSRCDCHRFFESINIVDIQLNGRLCVKNREVEGVCEGDAGSPLVYQYAESSHVAIGIVSAGFYVNCSVTNENPEIYT DLAYYSDWIIRTVDEPICIIH
HLClotting-factor1 (API81376, Hemiscorpius lepturus)

Chymotrypsin-like protease-1 (ABR21038,

Mesobuthus eupeus)

HLClotting-factor2 (API81377, Hemiscorpius lepturus)

chymotrypsin-like protease-1 (ABR21038, Mesobuthus eupeus)

\section{Alpha-amylase}

La-alpha-

MIVDCLLLWFWVSVVHCSYHEPNTQAGRSVLVHLFEWRWKDIAEECETFLGPYGFGGVQVSPANENGIIWEPHWNSVIRRP WFERYQPVSYKIATRSGNESEFRDMVRRCNNAGVRIYVDAVINHMTGDIGRGKGTGGSDFDPGALQYYGVPYGPSDFNGRD QCPSGSGDIENYQDKYQVRNCRLSGLADLNLSKEYVRDKIVEYLNFLIDIGVAGFRVDASKHMWPGDLKIIYEKLKNLNTEYFP VHRRPFIYQEVIDLGGGEAVKAEEYTDLGRVTEFRFGKHLGDVIRKNYNQRLKYLKNFGQDWGMVSGSNALTFIDNHDNQRG HGAGGFGSILTFFESRMYKMAVAFMLAWPYGLPRVMSSYNWPRYVENGKDKNDWIGPPHDDEYNTKPVVRNPDLTCGNGW VCEHRWHQIYSMVKFHNVAGFEPVDFWWDNDYQQIAFGRKGKGFLAINNENHNLDQTLPTGLPPGTYCDVISGKLEGDKCT GRSVKVEQDGKAKIFIDNSWEDPMLAIHVEAKLNDVLHNGNTGRNRNG
Pancreatic alpha-amylase-like (XP_023225708, Centruroides sculpturatus)

\section{Cysteine-rich venom protein}

LaCRVP1 MMHFILTCILFPQVIHLNGVVAKEIKYIFYSESDYCVLGERDCNTSIYAEDFLWPHNSNRAYMASGDVPELSASNMLKLEWDQN LANIAQRAAEQCIDDYPPTFHGKVECRQPDSSAVINFSWKQSQNLENVAKRIEERIFEWTEYIKYRYNDSSLHFYRGTGIFEDL WAKVVQATTWKVGCGLADSDAVNHDMEHHYTEVISCLYENTKLQPGDEIYKLGSPCSACPLGTRCIPGSNLCEVEPGNCPIP GNAKQDCAKNTERNTNRETLWKCDLKKYGEECEIVPSCSLLWSVDQQGNFKSISVTRDCVSANVFIKRIRIGKPSCFTFQYIKE GNRNEPSDTVVMGMVFNLESGDIIQVAKGEDATTWTDVMIDIPWTGVDIQVGVVARSFNDNFRKQQILMKDFHVSDSACLRD TEHFKPNLH

LaCRVP2
MFIPLALLTAIRLSLRDRCCYAEEFLANPSVVWETETVCPTTPTYAGSVKSKRNANPGTPIPLSDQDKMEIVNEHNKYRGQVSP PAANMRYMIYNEDVAYAAQLWANGCQFRHGRPQGSKFQKLVGQNIYKGPSGSYSFYMRLWHNEVRDFDMKSQQCNATMC GHYLQMVWAESFLIGCGQSHCRGKRRSYNLFVCHYYKAFESFHPYKVGRPCSMCDAEAGGFCYNNTCVSKEDCEREGWPC
HLAllergen3 (API81354, Hemiscorpius lepturus)

HLAllergen1 (API81352, Hemiscorpius lepturus) 
LaCRVP3

LaCRVP4

LaCRVP5

LaCRVP6

LaCRVP7

LaCRVP8

LaCRVP9
MEKNVLWLIVLHLSLIWVKSQRDVGIAKFTGNLSSAWVHKLRVDYRLKLRRVARLASMMNDSDRLEVIRLHNLYRSMVAPPAA DMEYMAWDDRLASLSQQWAEECKWRHGNPRHDFPTGLGQNLYRGSVRSVALAIRLWYEEHVDYRYHNLSCNPKKQCGHY TQMVWSKTHLVGCGVKNGCWKGFKHYIVCNYWPSHYKGEKPFEIGRPCSLCNSTKSGLCWNKSCVSRSQCEEYKLDCSCD LICHNCGKLDREKCTCICKDGWKGVDCSEPCVDTMEDCSLYHCIYHEYSRNHPCLKSCNVCKPVNADDLRNSCCDGVSCPH GYVLDLADIPCECKPLCPGPKCGSLLHGPYFTLMLFVLLLLKCSAL

MEWTFVCSIMLSFAPLTWGKTQFETERINVSYSWVHYGGMSRRARATSMMKDPDKLEITRLHNSYRSMVSPSAVDMEYMEW DDRIASVSQQWADRCTWKHSKDTAIADFPDGLGENLYRGWSSSPAYAMNLWYSEYTHYDIQNTSCKPGKVCGHYTQMVWS KSRLVGCGVKEGCWRDYRYYIVCNYSPPGNYKGEKPYQIGRSCSHCHSGSGLCSNKSCVDRSQCDKYNLDCSCDLVCLNC GELNRHSCTCKCKEGWKGVDCSEPCQDAQENCLVSACSYYERWPRGSHPCEKTCNVCKSVTPDSVQNTCCDGVTCPPGE LDLSERPCECKKLCSGPKCQSSLHEPHSLFLLVAMSIFLRCYAR

MAAVAVALVVLWITVTSGSANNDTCAERYTNITPEHTMCKSTNENCTFVRSSGEVFEEQLLRTHNLIRNSIRKYVGKKYHLATN MKLMVWDDELYEMARLHSLQCVEEPDCDLCHQIGDFPVEQNFAVKTFKSSEVDGNGPIRRLQAVIEEWAAELRSYDCDVVKV FRNTEGLPTNWTNIFRATTMLVGCASMTFLTDEPGTFKEVYVCNYGPANLTEGEEIYRTGRKPCSECEDDEGCDTEFKHLCFP ADMEEENIPEETELHNTFARNMVTKKFPRQRRRYLWNTDVARSYLDRRTENWRTTGGGVTGSYPDYRTGNWGNTGEGVTR SSHTYQCKRKSETSQLSESSILVMEQQGF

MEIFLAIPCLLTAFLPSISNERCSDSFGNYDQALFREGTRDESVQISWWTTTPISKETGDKTRTSEEKECPELYQRYSRNHTFC QVSNCDIIRKGVTEEDKNIILEFHNSLRSKLASGMEKRYCSLPSAANMMQIEWDDELAAVAEAHAELCVYGHDRGKRAVESFS VGQNLMLYGGDIKRWGDADGWYKEEVCFYSPEKNSPFRSGIYGHFTQVTWATTWKIGCGFASYRKNGKVEALYTCNYGPS GNVREGRHYIVGEPCSQCPPNTECSTEDPGLCKSKTCDGPQMRRPPSEDFILFCDFSHEDSEECNKVKVNGSREFSTRHIYT GNYKTVVLNAGESITIDLGKAQNDGGICTFVYSRFGPNNAKDAPGSVMEIKYESPNILPVPPRTIGPYGPTFFMAGTHMSYHGE LQNTLTLRALEGAEPQYFDIKMWGIRKGDCLMSLESD

MEIFLAIPCLLTAFLPSISNERCSDSFGNYDQALFREGTRDESVQISWWTTTPISKETGDKTRTSEEKECPELYQRYSRNHTFC QVSNCDIIRKGVTEEDKNIILEFHNSLRSKLASGMEKRYCSLPSAANMMQIEWDDELAAVAEAHAELCVYGHDRGKRAVESFS VGQNLMLYGGDIKRWGDADGWYKEEVCFYSPEKNSPFRSGIYGHFTQVTWATTWKIGCGFASYRKNGKVEALYTCNYGPS GNVREGRHYIVGEPCSQCPPNTECSTEYPGLCKSKTCDGPQMRRPPSEDFILFCDFSHEDSEECNKVKVNGSREFSTRHIYT GNYKTVVLNAGESITIDLGKAQNDGGICTFVYSRFGPNNAKDAPGSVMEIKYESPNILPVPPRTIGPYGPTFFMAGTHMSYHGE LQNTLTLRALEGAEPQYFDIKMWGIRKGDCLMSLESD

MDLLFAISCLLAAFLPCICNKRCSNIYGKYDQGTLSKGARDETFLSSWRNVIPINIERGEKTQFSERKECPELYQRYSADHTFCK KSTCSIIQKGVTEDEKNTILKFHNSLRSKLASGKEARYSKTPLPSAANMMQLEWDNELAAVAEAHAELCLYDHDANEQRAVEN FPVGQNLMQYNGDIRKWGDADMWYKDEVCFYSPQYNSPFNSGDFGHFSQVTWATTWKIGCGFTSYRKDGSEKALYTCNYG PAGNVPGGRHYIVGKPCSQCPPNTECSTEYPGLCKSKTSDGPQMKRPSSEDFILFCDFSQADPEECKKVKVSGSREFSTRHI YTGDYKTVVLNAGESISIDVGKAQNTGGICPFVYARFGPNNAKDPVGSVVEIQFSAPNIVPMPPSTVTPLGSFFVAGTHMMYD GELQSVLTLKAEQGAKPQYFDVKAWGVRKGSCGTSLGPK

MEVTSRPVTEANPVIGQPLLTWKWTHLYICARKRIRAIINLHFLTVETANMNLTLVVSILCLALFTCQVVYSQRCPEIYQRFSEDH TYCKHSTCQVIKSGVTDQDKKIILDMHNSYRNKVALGQEDTPQRQPPAANMLQMEWDDELARIAQAHANLCKFEHDSPDQRQ
HLAllergen2 (API81353, Hemiscorpius lepturus)

HLAllergen2 (API81353, Hemiscorpius lepturus)

HLAllergen7 (API81358, Hemiscorpius lepturus)

HLAllergen2 (API81353, Hemiscorpius lepturus)

HLAllergen2 (API81353, Hemiscorpius lepturus)

HLAllergen1 (API81352, Hemiscorpius lepturus) 
VENFNVGQNLFISMMTQVIDWNKTAMWYTWEIKHYYPQYREPFASGPYLHLSQMIWADTWKVGCGVAVYYDNNERRDKVLY TCNYGPGGNQIGQKVYTAGKPCSQCPKNTQCSSEYKGLCKSRTPDGPQQDTTRNPDDFLLYCDFSNNEDRACKNVQISGLR QFETRKIYGGEYKIAILKGGESITFKLGKAKDSRGICPFIYGSFGPNRAGDAKQSAVSIGFAASGLIFGDPIKIDYGSSDFWPIGM HMQYDQEMESTIKLEAYPGAPPQYFKIKAFGIGKGKCPKF

LaCRVP10

MDFLLAISCLLAAFLPCNSNHLCSELYGEYDEDSDEDYPSSEWEEIPTDEERGEKSQISERKECPELYQRYSTNHTFCKESTC DIIRRGITEEDKNTILEFHNSLRSKLASGKEARYSQTPLPSAANMMQMEWDDELAAVAQAHAELCIFNHEPDDQREVENFPVG QNLMQFDYDIKSWESAEIWYKEEVCFYSEEYNSPFNSGIFGHFSQLTWATSWKVGCGFASYRVNGSEKGLHTCNYGPPGNV AGGRHYIVGEPCSRCPPNTECSTEYPGLCKSKTSDGPQMKRPSSEDFILFCDFSQEDPEECDGVKVNGSREFSTRHLYIGDY KTVVLNAGESISIDLGKAQNTGGICPFVYARFGSNNAKDPAGSVLEIQFDAPNMWSMPPIRVNPYGDSFQVAGVQMMYDGEL QSILTFKAEEGAKPQYFDVKAWGIRRGSCETSLDPEDEN

\section{Insulin-like growth factor binding protein}

LaVP1 MGKFLLIALFLF
DAIGVCRKV

LaVP2

LaVP3
MALRFCFITLLLLGVILGAMTLRCRQCGTYECPPAPENCPVGKVKDICNCCDECGKNLGEECGGAWDMYGKCGKGLRCFKEP VEGDPFNAKGTCR

MWFRLVLFCVLVTSIYSLSCPCHELDLEEFCGPPPKDCPLGLTLDACACCQVCFLTEGEVCGGPWDVNGKCGAGLTCVKPPG QSDFVFDQSDGVCKKQ
HLAllergen2 (API81353, Hemiscorpius lepturus)

Venom insulin-like growth factor binding protein-1 (ABR21044, Mesobuthus eupeus)

Venom insulin-like growth factor binding protein-1 (ABR21044, Mesobuthus eupeus)

Venom insulin-like growth factor binding protein-1 (ABR21044, Mesobuthus eupeus) 
Table S3 Comparison of inhibition of HCV infection between pretreatment and postentry treatment with $\mathrm{LaPLA}_{2}-1$

\begin{tabular}{ccc}
\hline LaPLA $_{2}-1$ & \multicolumn{2}{c}{ Inhibition (\%) } \\
\cline { 2 - 3 }$(\mathrm{ng} / \mathrm{ml})$ & Pretreatment & Post-entry treatment \\
\hline 100 & $>99.9$ & $8 \pm 6$ \\
10 & $92 \pm 1$ & $<0.1$ \\
1 & $16 \pm 23$ & $<0.1$ \\
0.1 & $<0.1$ & n.t. $^{\text {a }}$ \\
\hline
\end{tabular}

${ }^{a}$ n.t., not tested. 
Table S4 Cytotoxicity of LaPLA $2-1$.

\begin{tabular}{rc}
\hline LaPLA $_{2}-1(\mathrm{ng} / \mathrm{ml})$ & Cell viability $(\%)$ \\
\hline 1000 & 79 \\
100 & 100 \\
10 & 100 \\
1 & 100 \\
\hline
\end{tabular}




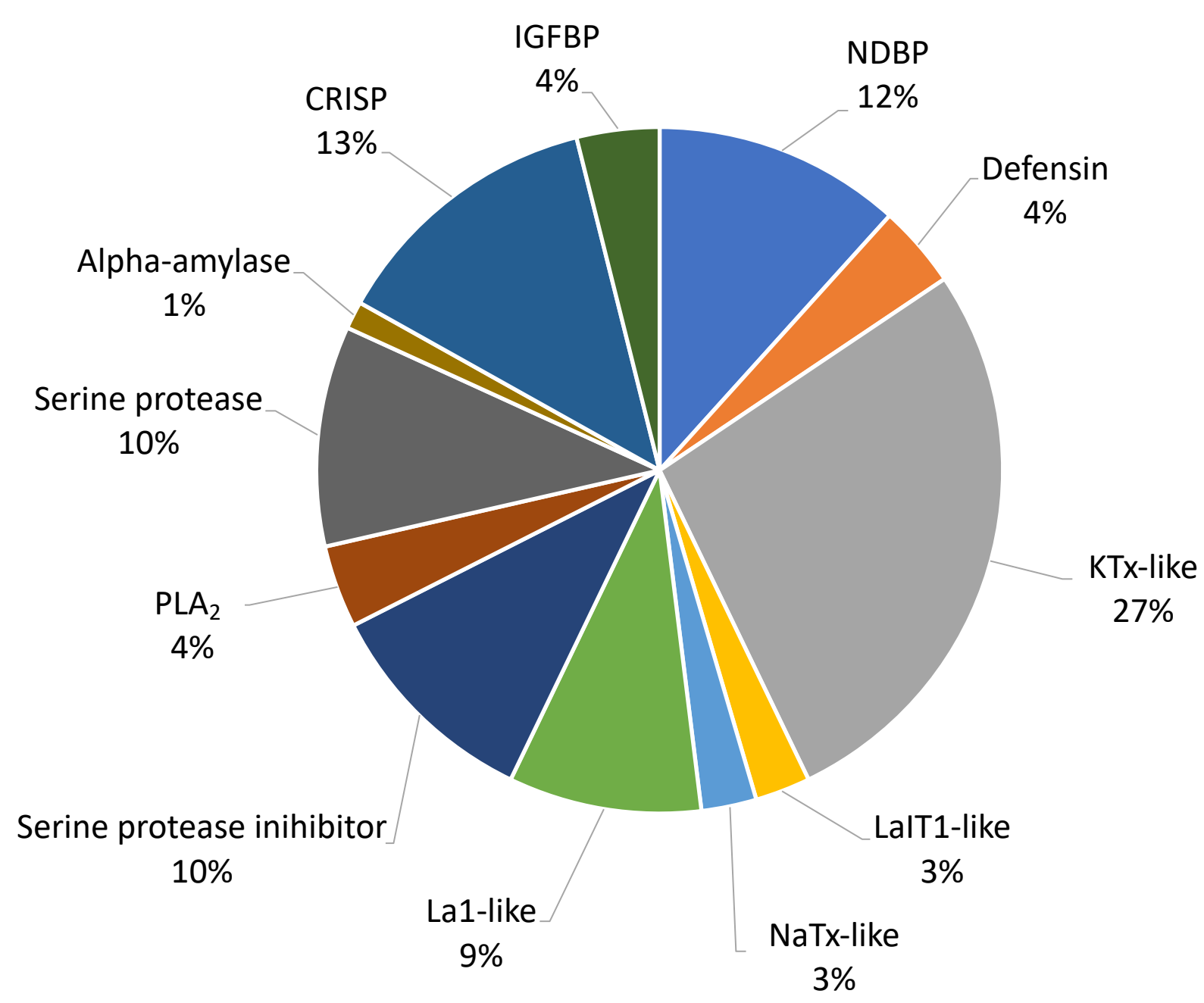

Figure 1. Proportion of the components identified by venom gland transcriptome analysis 
(a) NDBP

LaNDBP2-1 MNIKVVLVVCLITLLVTEQVEGGWFSRIKSLAKKAWKSNLAKDLRKMAGKAARNYAAKVLNVSPEEQVQL--DNLLRYL--D

LaNDBP2-2 MNGKVLVVCLIVAMLVMEPAEAGIWGWIKKTAKKVWNSDIANQLKNKALNAAKNYVAEKVGATPAEAGQMPFDEFMDIYY-S

Vejovine MNAKTLFVVFLIGMLVTEQVEAGIWSS IKNLASKAWNSDIGQSLRNKAAGAINKFVADKIGVTPSQAASMTLDE IVDAMYYD

$100\left(\frac{\circ}{\circ} I d\right)$

37

42

LANDBP3-1 MQYKTFLVIFLAYLLVTEEAQAFWWALAKGAAKLLPSVVGAFTKR-KREIEKIFDPYQSSLDLEMERFLRQLQ 100

LaNDBP3-2 MKLRTLMVIFLAYLIVTDEAEAFWGFLAKAAAKLLPSLFSSKKEKEKREIEHFFDPYEKELDSELDQLLYELQ 56

Heterin2 MQYKTFLVIFLAYLLVTEEALAFWGALAKGALKLIPSLVSSFTKKDKRALKNIFDPYQKNLDLELERLLSQLQ 75

LaNDBP4-1 MKIQLAILVITVVLMQMLVQTEAGFWGKLWEGVKNVIGKRGLRNKDQLDD-LFDSDLSDADAKLLREMFK 100

LANDBP4-2 MKIQLAILVITVVLMQMLVQTEASFWGKLWEGVKSAIGKRGLRDVDQMDD-LFDSDLSDADAKLLREIFK 90

LaNDBP4-3 MKNQFVILLLAIVFLQLFSQSEA-FLSALWGVAKSLFGKRGLKNLDQLDD-LFDGEVSEADLDFLKELMR 48

LaNDBP4-4 MKAOIVLLVITVVLMOMFAOSEAGFWGKLWEGVKSAIGKRGLRNLDOFDDELFDSDLSDADAKLLKEIFK

OcyC2 MKTOFAILMIAVVLMOMLVOTEGGILGKIWEGVKSLIGKRGLKKLDOLDD-TFDSDLSDADVKLLREMFK

LaNDBP4-5 MRLVSLTPLFLILLIAVDYCQSFP-FLLSLIPSAISALKKLGKRSTDFQRQLDFQRRYLNSDLDFDLDELEEFLDQLPDY

VPAmp1.0 MKLINLVPVFFVLIIVVDYCHSLPFFLLSLIPSAISAIKKIGKRSVESQRYVDLNRR----DLEQDLQELQDFLDQISEH

(b) Invertebrate defensin

$\begin{array}{llll}\text { LaDefensin1 } & \text { MKAIATLLLILVAFSVLEFGIVDAGFGCPFNRYQCHSHCQSIKRRGGFCAGTFRTTCTCYKSK------ } & 100 \\ \text { LaDefensin2 } & \text { MKAIATLLLLLVAFSILEDGIVDAGFGCPFNRYQCHSHCRSIGRRGGYCSGPFRFTCTCYK------ } & 85 \\ \text { LaDefensin3 } & \text { MKAIATILLLLAAFS ILEFGIVGAGFGCPHNRYCHSHCQSIGRNGGYCGGTFRTTCTCYNSGGPTSSP } & 74 \\ \text { AbDef-1 } & \text { MKTIVLLFVLALVFCTLEMGVVEAGFGCPFNQGRCHRHCRSIGRRGGYCRGIFKQTCACYRK------ } & 55\end{array}$

Figure 2. Multiple sequence alignment of NDBPs (a) and invertebrate defensin peptides (b) identified in this study and comparison with their similar peptides. Mature regions that were previously reported are underlined. Cys residues in the reported and putative mature regions are shaded in yellow. \%Id represents the percentage of sequence identity. 


\section{(a) Alpha-KTx}

La-alphaKTx1 MNAKFIYILLLTAVMFALYEASVPPNI PCQVTNQCPKPCREATGRPNSKCINGRCKCYG----La-alphaKTx2 MNTKFVFLLLVISTLMPTFDAS-AEDISCSSSKECYDPCEEETGCS SAKCVGGWCKCYGCRG--La-alphaKTx3 MNRNFVFLLLLIVTLMPMLDAA-TEDINCDNWRDCLKPCKDETGCPNSKCEEGNCLCYGCNRLTV Urotoxin

La-alphaKTx4 OcKTx2

La-alphaKTx5 Hemitoxin

La-alphaKTx6 La-alphaKTx7 LmKTx8

La-alphaKTx8 St20 MNAKLIYLLLVVTTMMLTFDTTQAGDIKCSGTRQCWGPCKKQTTCTNSKCMNGKCKCYGCVG---

MNKKFIFLLLVVTTLMPMFDA-ATEAISCSNPNDCREPCKKQTGCSGGKCMNRKCKCHRCNG MNAKF ILLLLVVTTTMLLPDTQGAEVIKCRTPKDCADPCRKQTGCPHGKCMNRTCRCNRC-G

MNAKLVCIVLL-TAVMFAPDEASLPPIRI PCYVSKDCRKPCLYLTGTPRSKCINRRCKCYG---MNTKFIFLFLVVTTTMLLFDTTAVEA--IKCTLSKDCYSPCKKETGCPRAKCINRNCKCYGCSG-

MNKPFCAIFLVVLIMFAVSVLPAES--TGGCPV-DSLCKSYCKSNKFGTEGKCDGTS---CKCAIG MNKLACYILICVMVSCLFKVPVAEGI-SAGCPLTAKLCTIYCKKHRFGREGKCIGPTRFRCKCYVMNKVCFVVVLVLFVALAAYVSP IEGVPTGGCPLSDSLCAKYCKSHKFGKTGRCTGPNKMKCKCLV-

--MRLVIILLLMTTLVLAVGAPLGGAKCSSSTQCTRPCRYAGGTHGKCMNGRCRCY--G MKMS IVIILLLFTCLIATNGA--SGTKCS GS PECVKFCRTKGCRNGKCMNRSCKCYLCS

La-alphaKTx9 MELKYLLVLLAVTCLVSCQDNSLLPSGSCSRTGICMESCAPFLYQPKYHRRCPAGYVCCTLIY Kbot55 --------------AGSMDSCSETGVCMKACSERIRQVENDNKCPAGECICTT--

\section{(b) Beta-KTx}

La-betaKTx1 (LaIT2) MAKHLIVMFLVIMVISSLVDCAKKPFVQRVKNAASKAYNKLKGLAMQSQYGCPIISNMCEDHCRRKKMEGQCDLLDCVCS

La-betaKTx2 (LaIT3) MQAQFTVLLLLVLVTLCSCGGILREKYFHKAADALTSNIPI PVVKDVLKSAANQMIRKIGKVQQACAFNKDLAGWCEKSCQEAEGKKGYCHGTKCKCGKPIDYRK

La-betaKTx3 MDTKLSILVFLCVVVIASCSWISEKRIQKALDEKLPKGFIQGAAKAIVHKFAKNQYGCLADMDVKGSCDRHCQETESTNGVCHGTKCKCGIGRVY 100

$\mathrm{SCl1}$

\section{(c) Kappa-KTx}

La-kappaKTx1 MKPSTSAYALLLVLTFGIIT--SGVFAVPMDEENTFEVEKRGNSCMEVCLQHEGNVAECEKACNKG La-kappaKTx2 MKPSTSAFILLLVLTFGIIT--SGVSAIPMDEENTFEEOKRDSACVEVCLHHEGNVAECEEACKKS HeTx203 MKTSGTVYVFLLLLAFGIFTDISSACSEQMDDEDSYEVEKRGNACIEVCLQHTGNPAECDKACDK-

\section{(d) Delta-KTx}

La-deltaKTx1 MASQFLLFCIVLIAVNPLVYSKG-GCRLPPETGLCYAYFERYYYDPSSNNCKMFVYGGCGGNSNNFVSKKACLARCAN--BmKTT-2 MMNVITVVGIILSVVCTISDAEGVDCTLPSDTGRCKAYFIRYFYNQKAGECQKFVYGGCEGNSNNFLTKSDCCKQCSPGKC

Figure 3. Multiple sequence alignment of KTx peptides identified in this study and comparison with their similar peptides. Mature regions that were previously reported are underlined. Cys residues in the reported and putative mature regions are shaded in yellow. \%Id represents the percentage of sequence identity. 
(a) $\mathrm{DDH}$

LaDDH1 (LaIT1)

LaDDH2

Phi-LITX-Lw1a

OcyC10

MNFATKVFFLLIAVAVIAIVAGEEDDSWFEONEESDTERDFPLSKEYETCVRPRKCOPPLKCNKAOICVDPKKGW-------------MNCAIKVSFLLLAITVIFSVAGGEGDNSFEQREENDTER DLPLSKKHESCVRPRKCRPPLRCNKAHICVESKKGWRI PVISWVSKTKIMFSE MNFATKVSLLLLAIAVIVIVEGGEGDSWFEEHEESDTERDFPLSKEYESCVRPRKCKPPLKCNKAOICVDPNKGW-_- - - - - - - MNFATKIVI LLLVAALI LAVTSEKGDSS SDDNEAKETEGELPLSDFYGSCVRPKKCKPHLKCNAAQICVFPKTGR-
100 ( $\% I d)$

(b) $\mathrm{NaTx}$

LaLAP1

LVP-1-alpha

MNTGEHFASLIIFLLLLGENPCLGDGGWPMRIDGNYYLCYYEEKPAELYCKRACKLHKASQSSCSYHWKYMSWYCYCEDLK-

MNI-KLFCFLS ILISLTGLSLSGDDGNYPIDANGNRYSC--GKLGENEFCLKVCKLHGVKRGYCYF------FKCYCELLKDKDIQFFDAYKTYCKN------------SRI

LaLAP2

-MLMVIYIATLIPLILQGECRAKDD---HPRNFEGNCYRCKYPDKSGYCEAICKMHKAETGYCSRSNLFCYCKGIEDKYVS-

$-A R D F L E P---$

100

BmLVP1-alpha

MMKFVLFGMIVILFSLMGS IRGDDDPGNYPTNAYGNKYYCTILGENEYCRKICKLHGVTYGYCYNSR--CWCEKLEDKDVTIWNAVKNHCTNTILYPNGK

(c) Ascaris-type protease inhibitor

LAAPI1 MKS--WTYRLCFLILFLVCV--NCT-RPVLSPEECTRPGEFFTTAGSYCPLTCDNYKN--P-PIICSLIGIVGCECSPELVRDERSGN-CVDTSDCTED----- 100

LAAPI2 MKG------FAFLVLTFVVVF-------GDKEQECEDPNAEFRRCNTACPITCANMDN--P-PNICTLQCVIGCACKEGYYKND-DGL-CVHPEGC-------- 33

LAAPI3 MKA--LLLLLSFVVIH--SAKSQEDLGGDEHAQSCLLPNEVWDKCGPSCPPSCIGVIE--P-GTLCSTECTPGCFCREGLVRTK-RGS-CIPPKACRNERETKL 25

LaAPI4 MKGSKPLCFLYLVVLLWTSV--KCT-RWASSSEECTRPGEAFTSCGTDCPITCANYEN--P-PEFCNYMCVIGCECTSGLVRDEGSGN-CVNPSQCGP------ 51

LAAPI5 MKR--NIVILAFVIT FCSIFEKCSAORCGADRRCRRPGEVFMNCGPSCPITCDNYON--P-PTVCTIOCVIGCFCRRGIVRDTRRCG-CVRPSOCRR--- -

LAAPI5 MKR- NLVLIAFVLLIFGSIFEKCSAQRGGADRRCRRPGEVEMVGPSCPLTCDNYQN--P-PTVCTLOCVIGCERRGLVRDTRRG CVRPSQCRR--L--

$\begin{array}{lll}\text { LaAPI6 } & \text { MKR--NLALSALFVLLFCSALDNCEAQRGGYDRTCQLEGEVFTRCGTACPLTCDNYKN--P-PEVCTLQCIIGCVCGRGWVKDTRRGR-CVRPSQCRR------ } \\ \text { LaAPI7 } & \text { MKS--NLVLFAFVLLLFCSVLEICTAQRRVVDRSCRGAGEVFTRCGTACPLTCDNYRN--P-PRFCTRQCIIGCACRRGWVKATRRGG-CVRPSQCRR------ }\end{array}$

LaAPI8 MAKT-----LAFGVVLCMFVLAQSAPQYPGTFG-C-DEDKQFVRCLPPCPVTCKS ILNTTP-CTLLLPRCTPGCGCRGGKILDN-AGK-CVFPADCRRG----- 22

SjAPI MKW--GALLCIFGFLAFCSVLDRGLGWIPDIWQKCSSKNEEFQQCGSSCPETCANHKN--PEPKSCAAVCFVGCVCKPGFIRDDLKGSICVKPEDCSK------

Figure 4. Multiple sequence alignment of DDH (a), NaTx (b), and Ascaris-type protease inhibitor peptides (c) identified in this study and comparison with their similar peptides. Mature regions that were previously reported are underlined. Cys residues in the reported and putative mature regions are shaded in yellow. \%Id represents the percentage of sequence identity. 


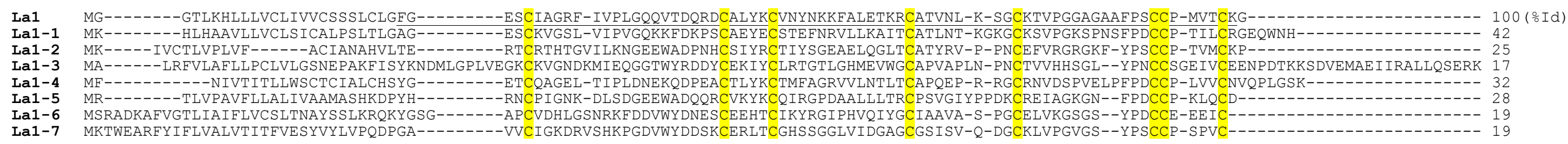

Figure 5. Multiple sequence alignment of La1-like peptides identified in this study. Mature regions that were previously reported are underlined. Cys residues in the reported and putative mature regions are shaded in yellow. \%Id represents the percentage of sequence identity. 
a)

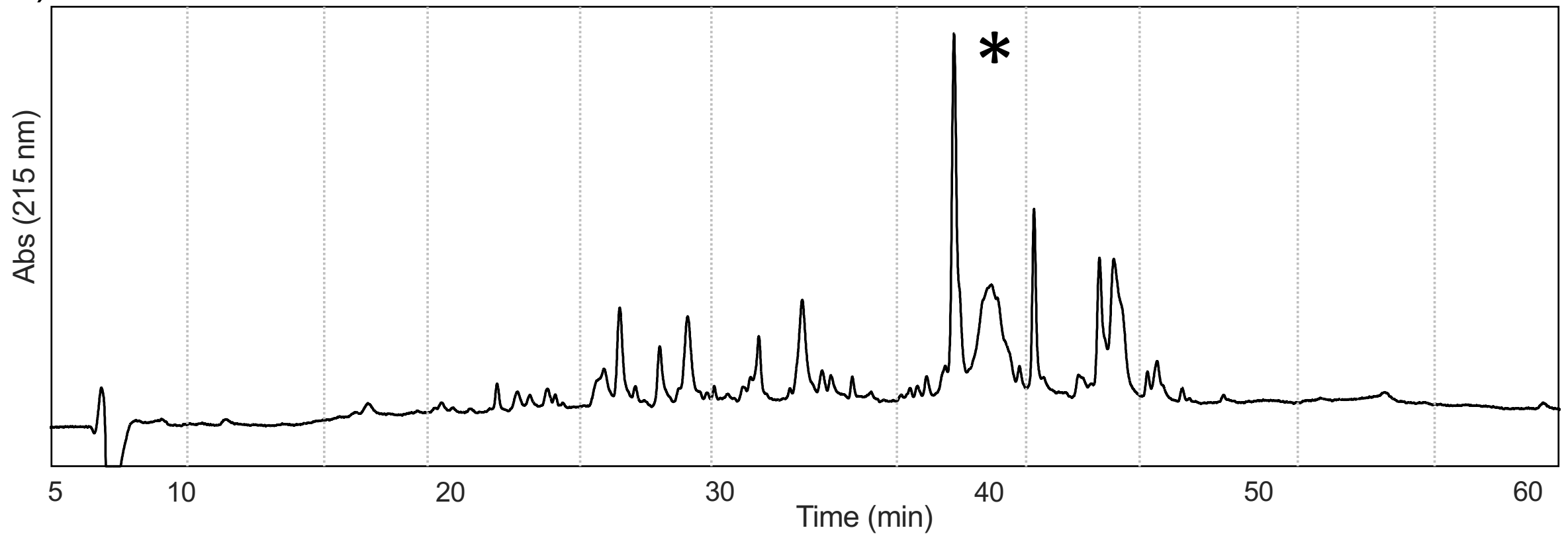

b)

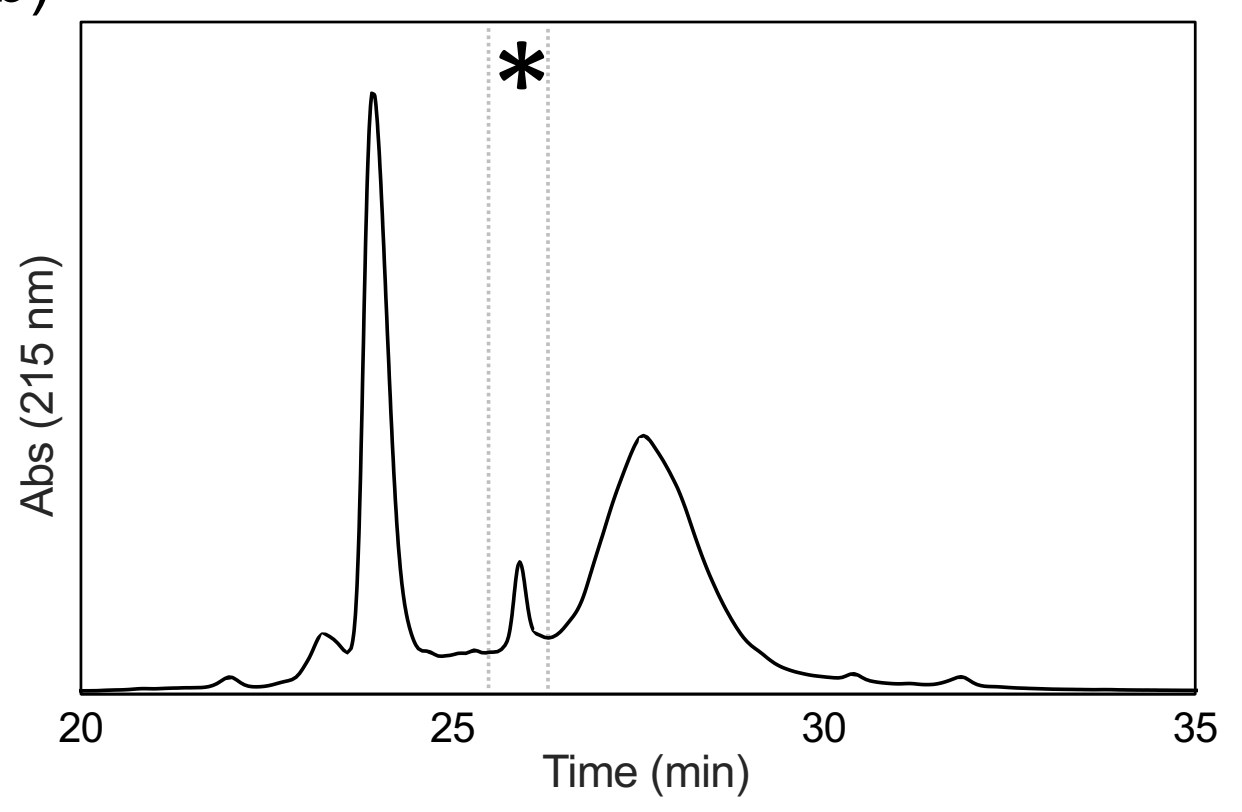

C)

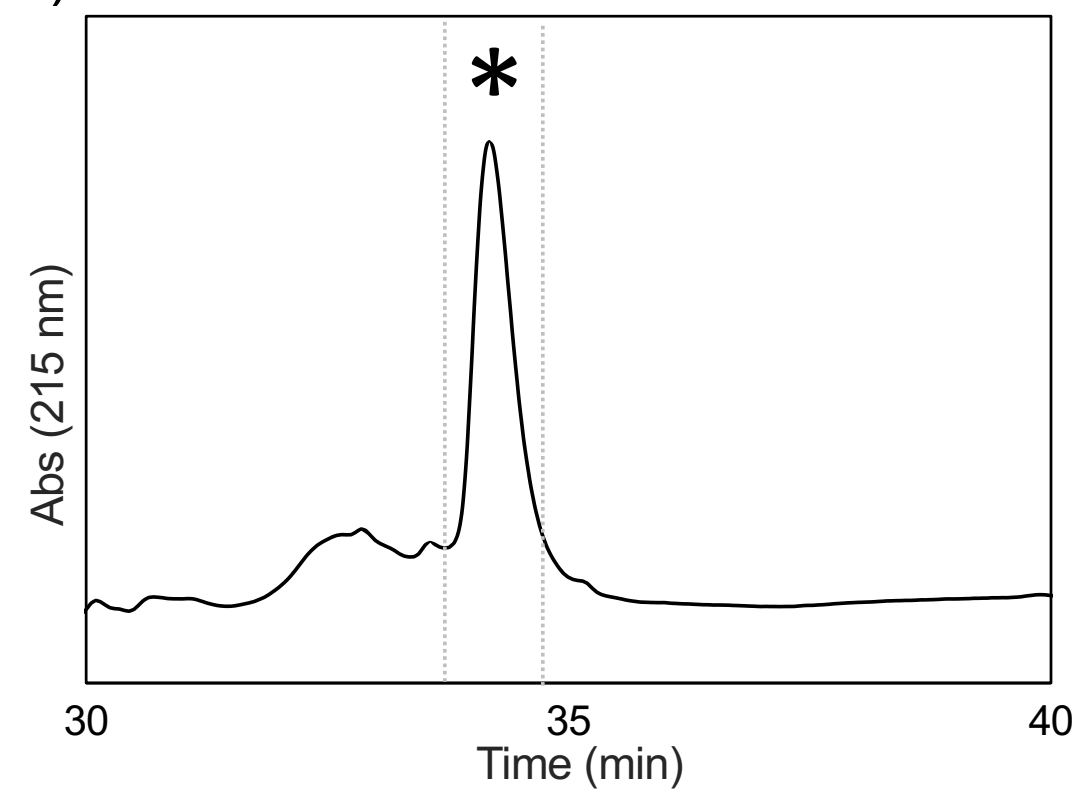

Figure 6. HPLC purification of an anti-HCV component from the venom. (a) First separation using a C4 column. (b) Second purification using a C18 column. (c) Final purification using a C18 column. Asterisks indicate fractions showing anti-HCV activity. 
a)

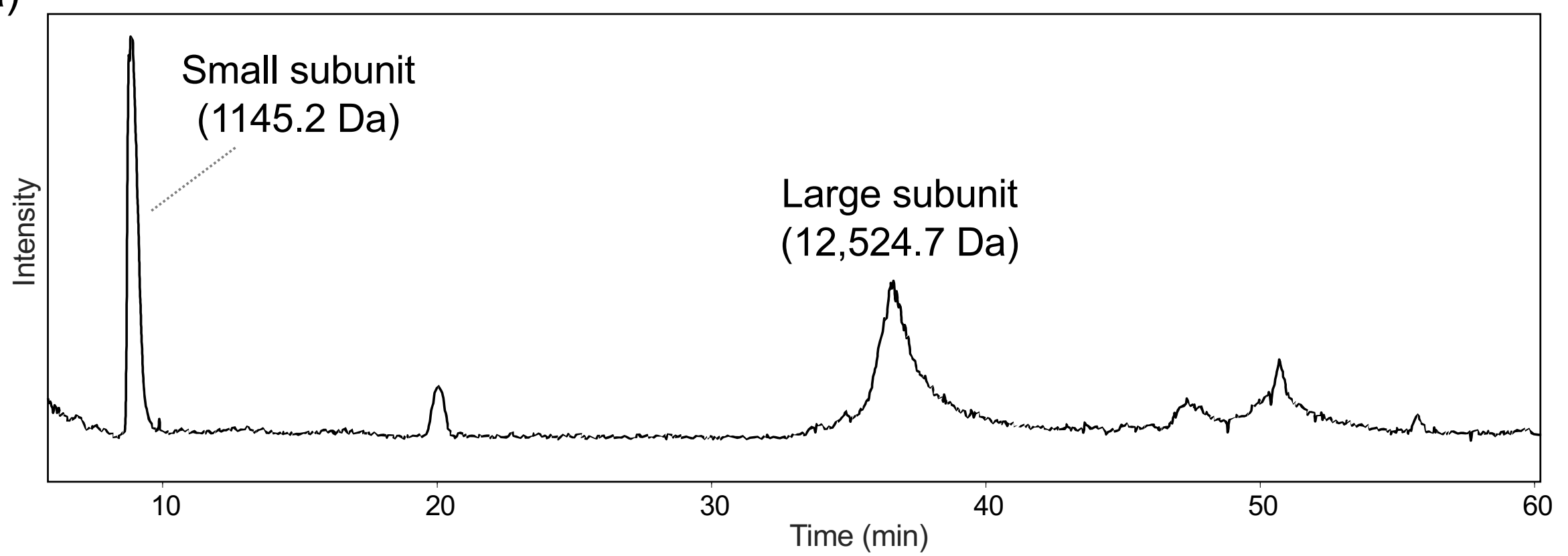

b)

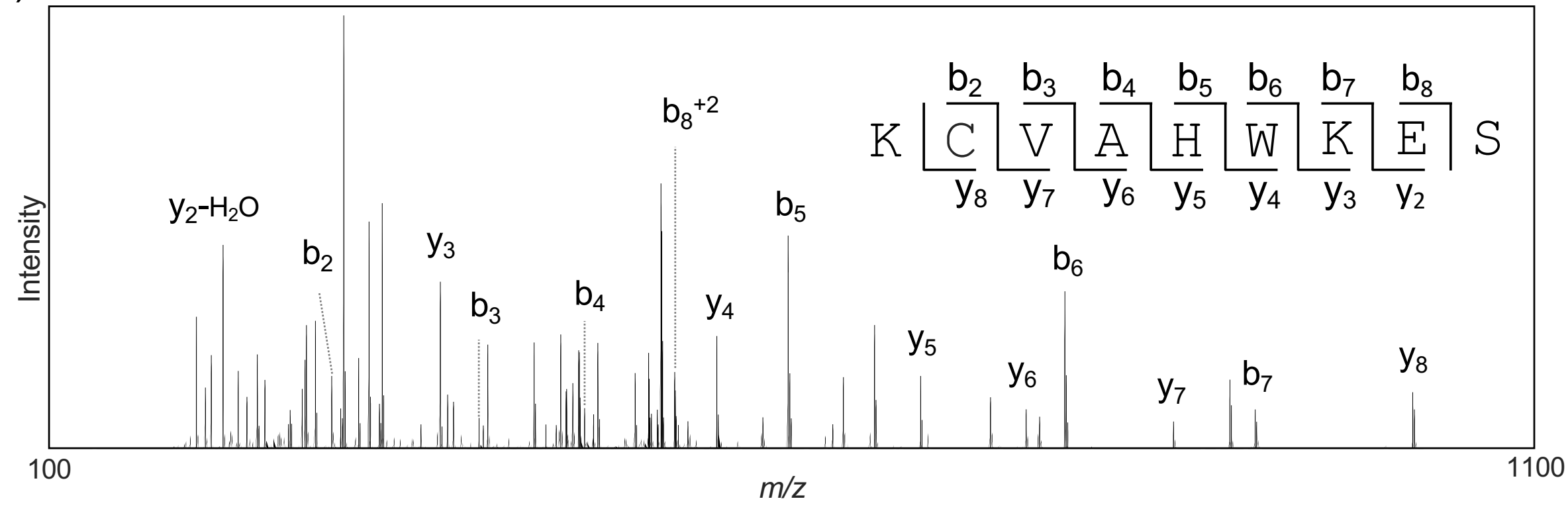

Figure 7. LC/MS analysis of the anti-HCV component after reduction/alkylation reactions. (a) TIC chromatogram of the reaction mixture. (b) Product ion spectrum of the small subunit. 


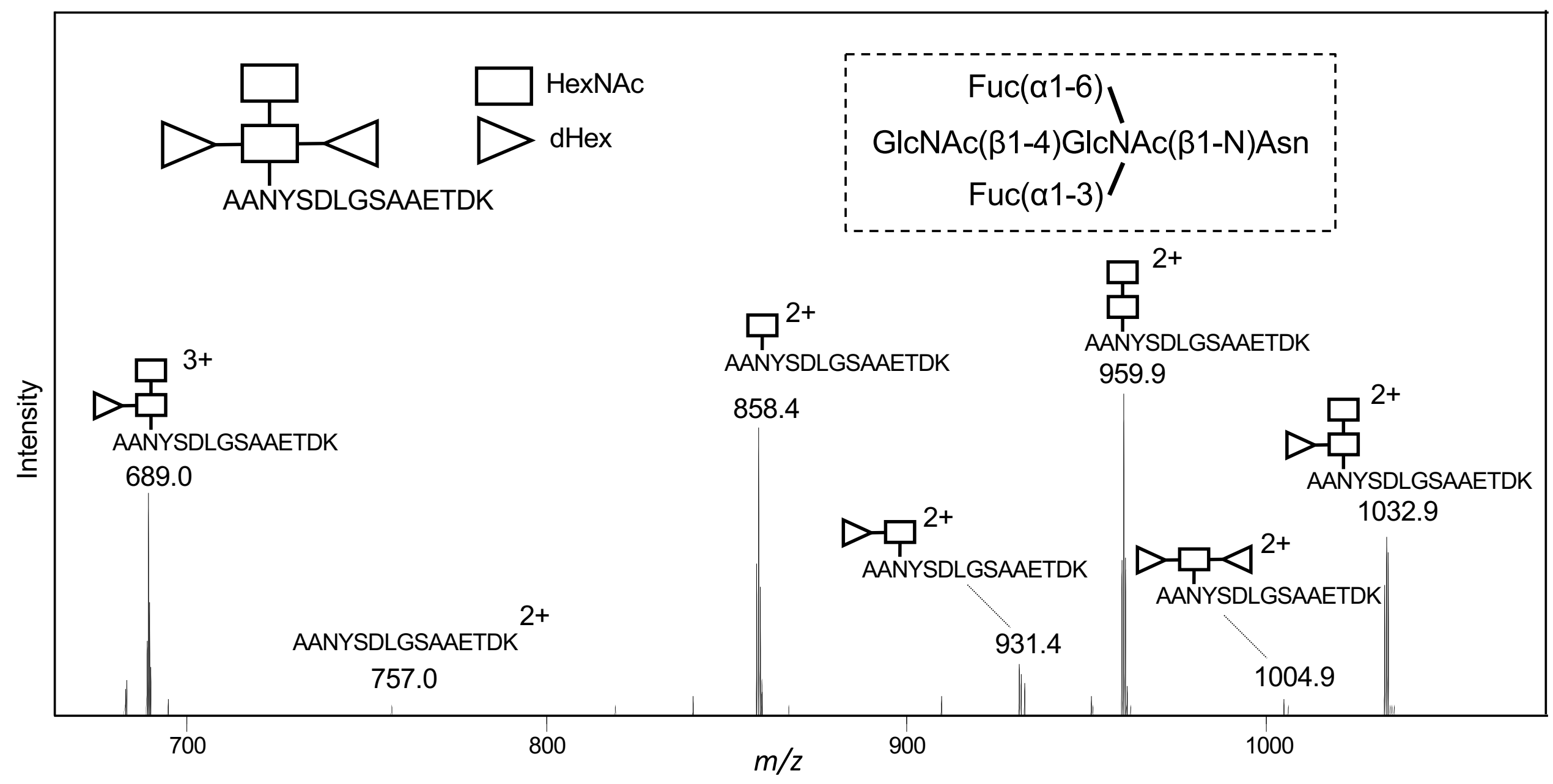

Figure 8. Product ion spectrum of the Lys-C digest containing N-glycosylation and its estimated glycan structure (dashed square). 


\section{LaPLA $A_{2}-1$ Hemilipin \\ $\mathrm{HgPLA}_{2}$ \\ Phaiodactylipin \\ $\mathrm{BvPLA}_{2}$}

\section{$\operatorname{LaPLA}_{2}-1$ \\ Hemilipin \\ $\mathrm{HgPLA}_{2}$ \\ Phaiodactylipin \\ $\mathrm{BvPLA}_{2}$}

LaPLA $A_{2}-1$

Hemilipin

$\mathrm{HgPLA}_{2}$

Phaiodactylipin

BvPLA 2

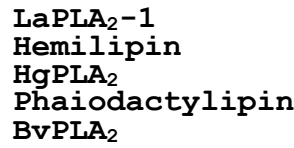

LaPLA $A_{2}-1$ Hemilipin

HgPLA 2

Phaiodactylipin

$\mathrm{BvPLA}_{2}$

LaPLA $2-1$

Hemilipin

HgPLA 2

Phaiodactylipin

BvPLA $_{2}$
MVFIFLAVLSGLVTLSHSTAVQREMHVHFEPLPGQRDSWPVARAALVNLATKSETGRE -MTFLILTILATVTPSLYS HVVORELRVNFEPLAGORDSWPVARAAMVTFDARSEKARE - MSLIIVLVISVL---SADAVLSMDNELYLNLEP SQRS SWPVARAVRMQFSKRSEGGRESR

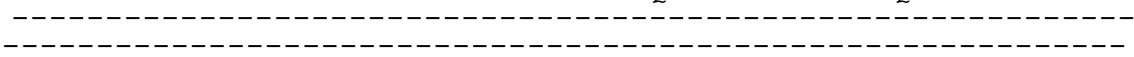

FSDCRMLNS IDEIAREGAVI SRYETKRVSKEEMRSLEKRCSRSSGIHORI TFPGTK $\nabla \nabla \nabla$ -FSECRMINSMHE LSRELMDS PEHTVKRASKEEMDDLVORCSGSAEGRSWF'WPDTKWCG KMQGCQILES LNDIAREALRTPRHTTKRISKDEMEFFEGRCLSVGESER--TVLGTKWCG -------------------MVKRVSKEEMDALERSCSOPFEEERFLIVSGTKWCG -----MQVVLGS LFLLLL---------S-TSHGWQ I RDR I GDNELEERIIYPGTLWCG

$\nabla \nabla$
AGDKAANYSDLGSAAETDKCCRAHDHCDN-IAAGETKYGLENSYWFTKLNCKCEESFRNC PGTDAKNESDLGP-LEADKCCRTHDHCDY-IGAGETKYGLTNKSEFTKLNCKCEAAFDQC AGNEAANYSDLGYFNNVDRCCREHDHCDN-IPAGETKYGLKNEGTYTMMNCKCEKAFDKC NNNIAANYSDLGF-LEADKCCRDHDHCDH-IASGETKYGLENKGLF'TILNCDCDEAF'DHC HGNKSSGPNELGRFKHTDACCRTHDMCPDVMSAGESKHGLTNTASHTRLSCDCDDKFYDC

LAEAKKKET-------TAKFVKFSYFNVYGPKCFVLDCDKRRFEM--SRK--------LKESIDRAEGS--AKSSMEGLHS FYFNTYSPECYEVKC SRKRDAE--CT $\bar{N}---------$ LSDISGYFTRK-----AVSAVKFTYFTLYGNGCYNVKCENGRSPSNECPN--------LKEISNNVTTDIRQKGGAENVWRFYFQWYNANCYRLYCKDEKSAR--DEA--------LKNSADTIS-------SYFVGKMYFNLIDTKCYKLEHPVTGCGERTEGRCLHYTVDKSK

$\begin{array}{ll}\text {-CVAHWKESRRG--------- } & 100(\% \text { Id) } \\ \text {-GIAIWKDSYKS-------- } & 49 \\ \text {-GVAEYI'GE'T-LGAKVINFGK } & 41 \\ \text {-CTNQYAVKKNFTVQ----- } & 46 \\ \text { PKVYQWFDLRKY--------- } & 26\end{array}$

Figure 9. Multiple sequence alignment of $\mathrm{LaPLA}_{2}-1$ and its related $\mathrm{PLA}_{2}$ molecules. Mature regions that were experimentally determined are underlined. Cys residues in the mature regions are shaded in yellow. Open triangles indicate the $\mathrm{Ca}^{2+}$-binding motif. Closed triangles indicate the catalytic dyad. N-glycosylation motif is shown in bold. The N-glycosylation sites that were experimentally confirmed are shown in red. \%Id represents the percentage of sequence identity. 


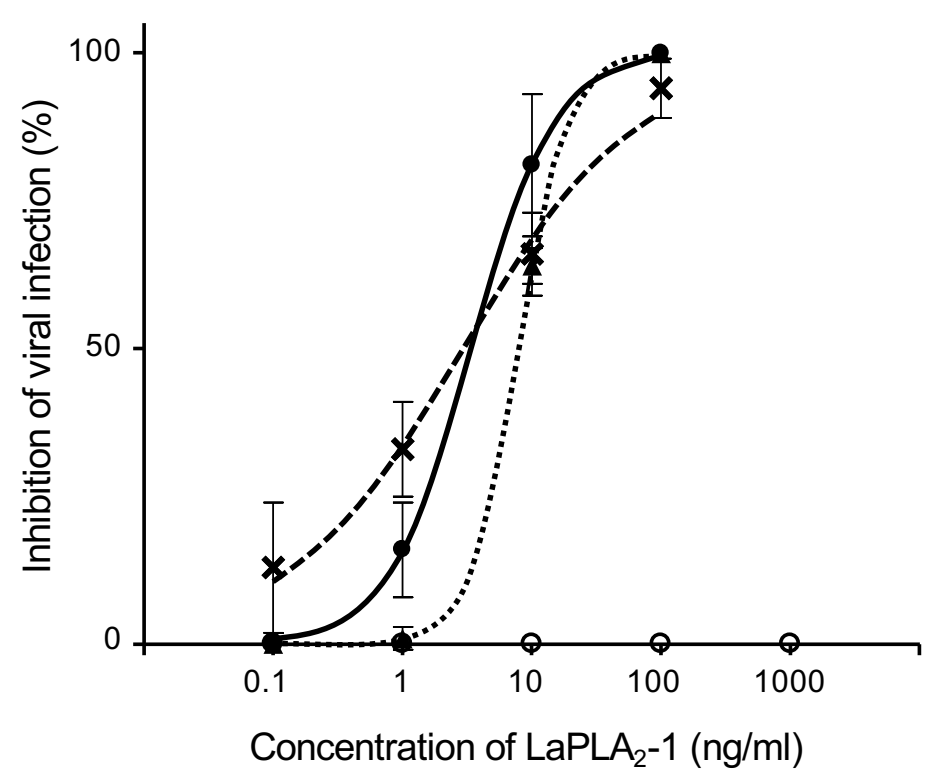

Figure 10 Representative concentration-inhibition curves for $\mathrm{LaPLA}_{2}-1$ on $\mathrm{HCV}(\mathbf{O})$, $\operatorname{DENV}(\boldsymbol{X}), \operatorname{JEV}(\boldsymbol{\Delta})$, and HSV-1 $(\mathrm{O})$ infection. Each point represents means $\pm \mathrm{SEM}$. 


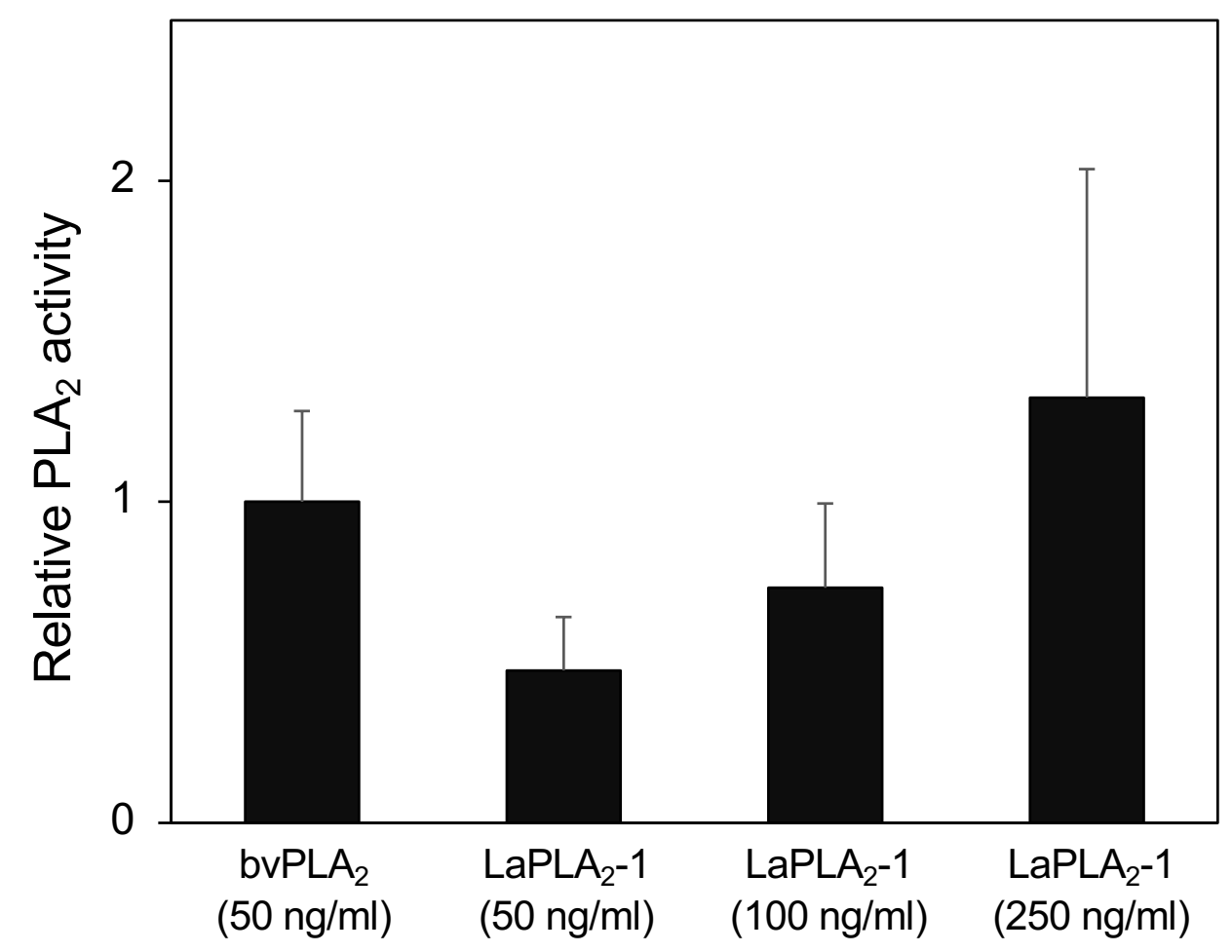

Figure 11. Comparison of $\mathrm{PLA}_{2}$ activity between bvPLA $A_{2}$ and $\mathrm{LaPLA}_{2}-1$ 


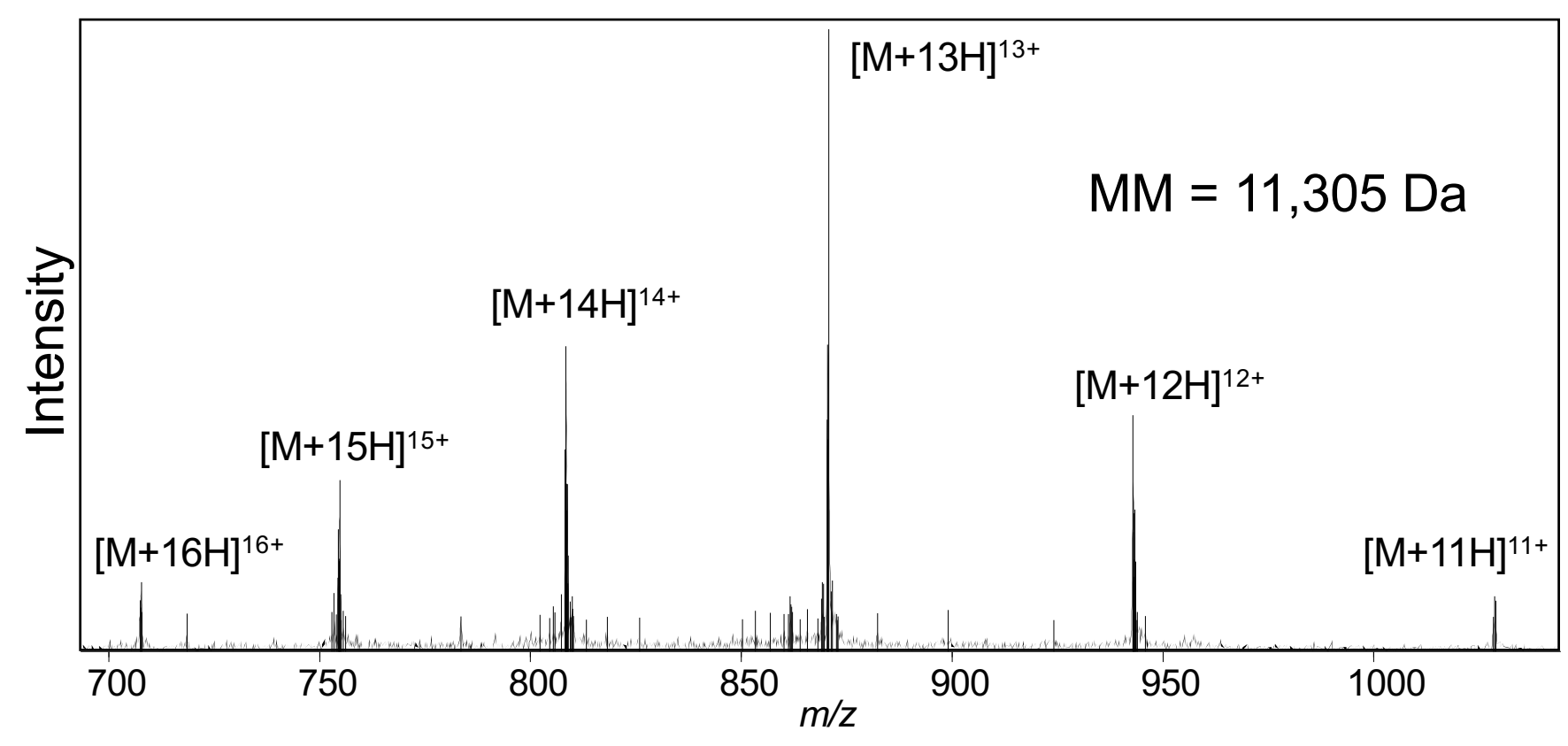

Figure S1 Mass spectrum of $\mathrm{LaPLA}_{2}-1$ after deglycosylation 